\title{
On the Vertical Velocity and Nutrient Delivery in Warm Core Rings
}

\author{
KE CHEN \\ Physical Oceanography Department, Woods Hole Oceanographic Institution, Woods Hole, Massachusetts \\ Peter GAube \\ Applied Physics Laboratory, University of Washington, Seattle, Washington \\ ENRIC PALLÀS-SANZ \\ Department of Physical Oceanography, Ensenada Center for Scientific Research and Higher Education, \\ Ensenada, Mexico
}

(Manuscript received 28 September 2019, in final form 5 March 2020)

\begin{abstract}
We examine various contributions to the vertical velocity field within large mesoscale eddies by analyzing multiple solutions to an idealized numerical model of a representative anticyclonic warm core Gulf Stream ring. Initial conditions are constructed to reproduce the observed density and nutrient profiles collected during the Warm Core Rings Program. The contributions to vertical fluxes diagnosed from the numerical simulations are compared against a divergence-based, semidiagnostic equation and a generalized omega equation to better understand the dynamics of the vertical velocity field. Frictional decay alone is found to be ineffective in raising isopycnals and transporting nutrients to the upper ocean. With representative wind forcing, the magnitude of vorticity gradient-induced Ekman pumping is not necessarily larger than the current-induced counterpart on a time scale relevant to ecosystem response. Under realistic forcing conditions, strain deformation can perturb the ring to be noncircular and induce vertical velocities much larger than the Ekman vertical velocities. Nutrient budget diagnosis, together with analysis of the relative magnitudes of the various types of vertical fluxes, allows us to describe the time-scale dependence of nutrient delivery. At time scales that are relevant to individual phytoplankton (from hours to days), the magnitudes of nutrient flux by Ekman velocities and deformation-induced velocities are comparable. Over the life span of a typical warm core ring, which can span multiple seasons, surface current-induced Ekman pumping is the most effective mechanism in upper-ocean nutrient enrichment because of its persistence in the center of anticyclones regardless of the direction of the wind forcing.
\end{abstract}

\section{Introduction}

Mesoscale eddies are energetic structures that often involve large-amplitude anomalies in density and sea surface height (SSH), the latter of which can be detected by satellite altimeters (e.g., Chelton et al. 2011a). Eddies influence the marine environment by transporting properties such as heat, salt, carbon, nutrients, and ecosystem over large distances. Furthermore, mesoscale eddies have significant influence on the flux of nutrients into the sunlit surface ocean in oligotrophic ecosystems (McGillicuddy and Robinson 1997; Oschlies 2002; McGillicuddy et al. 2007). The processes by which

\footnotetext{
Corresponding author: Ke Chen, kchen@whoi.edu
}

mesoscale eddies influence the vertical nutrient delivery can be segregated into vertical mixing (Dewar 1986; Nelson et al. 1989) and vertical advection as a result of eddy pumping (McGillicuddy and Robinson 1997), eddy-induced Ekman pumping (also known as eddywind interaction) (Dewar and Flierl 1987; McGillicuddy et al. 2007; Gaube et al. 2013), and wind-sea surface temperature (SST) interaction (Chelton et al. 2004; Xie 2004; Gaube et al. 2015). Eddies also affect the horizontal distribution of nutrients and ecosystems by both stirring ambient fields (i.e., advecting tracers around eddy peripheries) (Chelton et al. 2011b; Siegel et al. 2011; Gaube et al. 2014) and trapping water parcels during formation, resulting in the advection of ecosystems, nutrients, and other water properties away from 
the region of eddy formation (Early et al. 2011; Lehahn et al. 2011).

Large-amplitude eddies are common in western boundary current systems, such as the Gulf Stream. Long-lived and large-amplitude anticyclonic Gulf Stream eddies, often referred to as Gulf Stream warm core rings (WCRs), are generated when anticyclonic meanders of the Gulf Stream pinch off. It has long been recognized that Gulf Stream WCRs can exert significant impact on the coastal environment in the northwest Atlantic. (e.g., Garfield and Evans 1987; Joyce et al. 1992; Gawarkiewicz et al. 2001; Ryan et al. 2001; Lee and Brink 2010; Chen et al. 2014; Zhang and Gawarkiewicz 2015). The associated shelf-slope exchanges would significantly influence the biogeochemical processes, for example, carbon cycling, and marine ecosystem in the shelf-slope region (e.g., Fennel et al. 2006; Hofmann et al. 2011; Friedrichs et al. 2019).

While the importance of mesoscale eddies in physical and biological processes has been recognized, contrasting results exist regarding the role of the WCRs in the upper-ocean ecosystem. Anticyclonic eddies in the Gulf Stream region are often considered lower in surface phytoplankton biomass when compared to the surrounding waters (e.g., Gaube et al. 2014). Consistent with the eddy-pumping mechanism, but inconsistent with the mechanism of eddy-induced Ekman pumping/eddy-wind interaction, low (high) chlorophyll a concentration (CHL) in the shelf-slope region of the northwest Atlantic is associated with warm (cold) core eddies (He et al. 2010; McGillicuddy 2016). However, a number of studies have clearly demonstrated that individual anticyclonic WCRs can be associated with high biomass and/or high productivity in the northwest Atlantic and other western boundary current regions (Tranter et al. 1980; Scott 1981; Nelson et al. 1985; Smith and Baker 1985; Nelson et al. 1989; Sasaki and Hiroe 2002; Dufois et al. 2016). In addition, it has been suggested that the dominant mechanism for the biogeochemical response to mesoscale eddies varies across regions (Gaube et al. 2014). Apparently, a better understanding of multiple physical mechanisms for the vertical nutrient enrichment within mesoscale eddies is needed.

One fundamental process in material transport in eddies and rings is the vertical velocity, which has been a subject of continuous study. Various mechanisms have been suggested for the generation of vertical motions within mesoscale eddies including frictional decay (Flierl and Mied 1985; Franks et al. 1986), Ekman pumping (e.g., Martin and Richards 2001; McGillicuddy et al. 2007; Mahadevan et al. 2008; McGillicuddy 2015), surface temperature-induced wind stress change (e.g., Chelton et al. 2001; Small et al. 2008; O'Neill 2012;
Gaube et al. 2015), ageostrophic advection of vorticity and straining deformation (e.g., Pallàs-Sanz and Viúdez 2005; Barceló-Llull et al. 2017; Zhang et al. 2019), vortex tilting (e.g., Koszalka et al. 2009; Viúdez 2018), vortex Rossby waves (e.g., McWilliams et al. 2003; Nardelli 2013), and mixed layer submesoscale instabilities (e.g., Brannigan 2016). Because these mechanisms can operate at vastly different scenarios and are modulated by both the ocean and the atmosphere, it is challenging to quantify their relative roles in vertical material transport and marine ecosystem response.

Indirect inference of vertical velocity from in situ observations can provide a representation of the actual velocity field and the dynamical processes but is limited by the synoptic nature of the observations and the assumptions made in order to interpret the results. Direct measurements of vertical velocities can be made with neutrally buoyant Lagrangian floats equipped with acoustic Doppler current profilers (Shcherbina et al. 2018), yet again, these are limited to very small-scale synoptic processes. On the other hand, numerical simulations can offer a comprehensive view of vertical processes in mesoscale eddies and their manifestations. However, understanding of each embedded process is not always straightforward because of the concurrently operating processes at any given time. For example, the biological consequences of the frictional decay of WCRs are the same as that occurring from eddy-induced Ekman pumping and, as such, the biological response to these two mechanisms cannot be differentiated from observations alone or numerical simulations that include both processes. Similarly, the effects of Ekman pumping velocities always coexist in observations and numerical models that consider the relative wind to the ocean current. It is therefore challenging to estimate the relative contribution of each process in upward tracer flux across different spatial and temporal scales.

The objective of this study is to elucidate the physical mechanisms for vertical motions in large anticyclones, modeled here after Gulf Stream warm core rings, using idealized numerical simulations. Philosophically, this approach is to gain a representative view of the vertical velocity field and the delivery of nutrients in a typical warm core ring. This is the foundation for understanding vertical processes in more complex settings. Without the fundamental understanding of various processes in a stand-alone WCR, it is difficult to interpret the observed biological response to vertical transport in mesoscale eddies (e.g., the surface chlorophyll signature of eddies). These WCRs impact the biogeochemical environment and marine ecosystem in the slope region, where they eventually decay (or reattach to the Gulf Stream). Therefore, 
detailed investigation on the physical processes controlling the nutrient delivery related to the WCRs is vital for improved understanding of ecosystem dynamics and biogeochemical cycling not only in the open ocean where eddies propagate, but also for coastal and shelf ecosystems.

\section{Data and methods}

\section{a. Historical observations}

A multidisciplinary program focusing on the WCRs in the northwest Atlantic was carried out in the early 1980s (Schink et al. 1982). During the field program, a variety of observations, including physical, chemical, and biological measurements, was made. Among all profiles containing concentrations of the macronutrient nitrate, 75 quality-controlled temperature/salinity/nitrate profiles near the centers of warm core ring $81 \mathrm{D}, 82 \mathrm{~B}, 82 \mathrm{E}$, and $82 \mathrm{H}$ are used. It is worth noting that only the profiles within the ring, not in the radial section or slope sea, are chosen. In total, there are 828 data points, which are used to construct the initial condition of the numerical experiments (section $2 \mathrm{~b}$ ) and the nitrate-density relationship (section 4).

\section{b. Numerical modeling}

The main purpose of this work is to identify and quantify the processes leading to vertical motions in the targeted warm core ring in various scenarios. Realistic or idealized simulations, including mesoscale eddies and other dynamical processes, provide an overview of the greater eddy field and how eddies interact with each other and other current or bathymetric features, but unraveling each physical process involved is difficult. In this study, an idealized numerical modeling approach is taken to separate irrelevant processes from the processes of interest. This approach allows one to understand the processes from the simplest setting, based on which a systematic understanding can be further developed.

The model is based on the hydrostatic Regional Ocean Modeling System (ROMS). The ROMS is a freesurface, primitive equation model in widespread use for estuarine, coastal, and basin-scale ocean applications (www.myroms.org/papers). ROMS employs splitexplicit separation of fast barotropic and slow baroclinic modes and is formulated in vertically stretched terrain following coordinates using algorithms described in detail by Shchepetkin and McWilliams (2005) and Haidvogel et al. (2008). A redefinition of the barotropic pressure gradient term (Shchepetkin and McWilliams 2005) is also applied in ROMS to reduce the pressure gradient truncation error.
The model is configured on an $f$ plane with a Coriolis frequency of $9.6 \times 10^{-5} \mathrm{~s}^{-1}$ corresponding to a reference latitude of $41^{\circ} \mathrm{N}$. The bottom bathymetry is flat at $2004 \mathrm{~m}$ to isolate processes involved with ring propagation and ring-topography interaction. The model domain is $1200 \mathrm{~km} \times 1200 \mathrm{~km}$, with a horizontal resolution of $1 \mathrm{~km}$, capable of resolving mesoscale and larger submesoscale processes (e.g., Capet et al. 2008; Brannigan et al. 2017). There are 60 vertical layers in the model with higher resolution near the surface and bottom in order to better resolve ocean boundary layers. The vertical mixing scheme is a $k$-profile parameterization (KPP; Large et al. 1994). Bottom stress was calculated using a quadratic method with a drag coefficient of 0.003 . To eliminate the reflection of waves generated by the local processes, for example, Rossby adjustment and wind forcing, radiation open boundary conditions, and sponge zones with increased horizontal viscosity are used. The sponge zone is $300 \mathrm{~km}$ wide and is circular shaped to eliminate any potential numerical asymmetry, with horizontal viscosity linearly increasing to 1000 times of the interior value (see below). In addition, 2D momentum boundary conditions were implemented using an explicit Chapman (Chapman 1985) and Shchepetkin scheme (Mason et al. 2010). We have conducted numerous sensitivity experiments to test these numerical configurations, including the shape of the model domain (rectangle and square), size of the domain $(600,1200$, and $2400 \mathrm{~km}$ width), options of open boundary conditions (radiation, gradient, and periodic), and the implementation of the sponge zone (shape, width, and viscosity). In the end, the chosen setup described above effectively eliminates wave reflections, and at the same time is computationally affordable.

To account for the unresolved processes below $1 \mathrm{~km}$ and to alleviate gridscale numerical noise, Laplacian horizontal diffusion and viscosity were used. In the control run, the Laplacian coefficients for tracer and momentum are $1 \mathrm{~m}^{2} \mathrm{~s}^{-1}$. Numerically, this corresponds to a damping time scale $\tau$ of gridscale waves of 2-3 days as $\tau \approx A^{-1}(2 / \Delta)^{-2}$, where $A$ is the Laplacian viscosity and $\Delta$ is the grid spacing (Griffies and Hallberg 2000). Physically, for a horizontal scale of $1 \mathrm{~km}$, this value is well within the range of observed diffusivity based on dye-release experiments (Okubo 1971) across the global oceans and in the northwest Atlantic open ocean (LatMix field experiment; Shcherbina et al. 2015), and in the northwest Atlantic coastal ocean (Rypina et al. 2016). In other words, this conservative value should make the choice of Laplacian operator versus biharmonic or adaptive (e.g., Smagorinsky 1963) operators less deterministic in affecting the major results of the numerical 

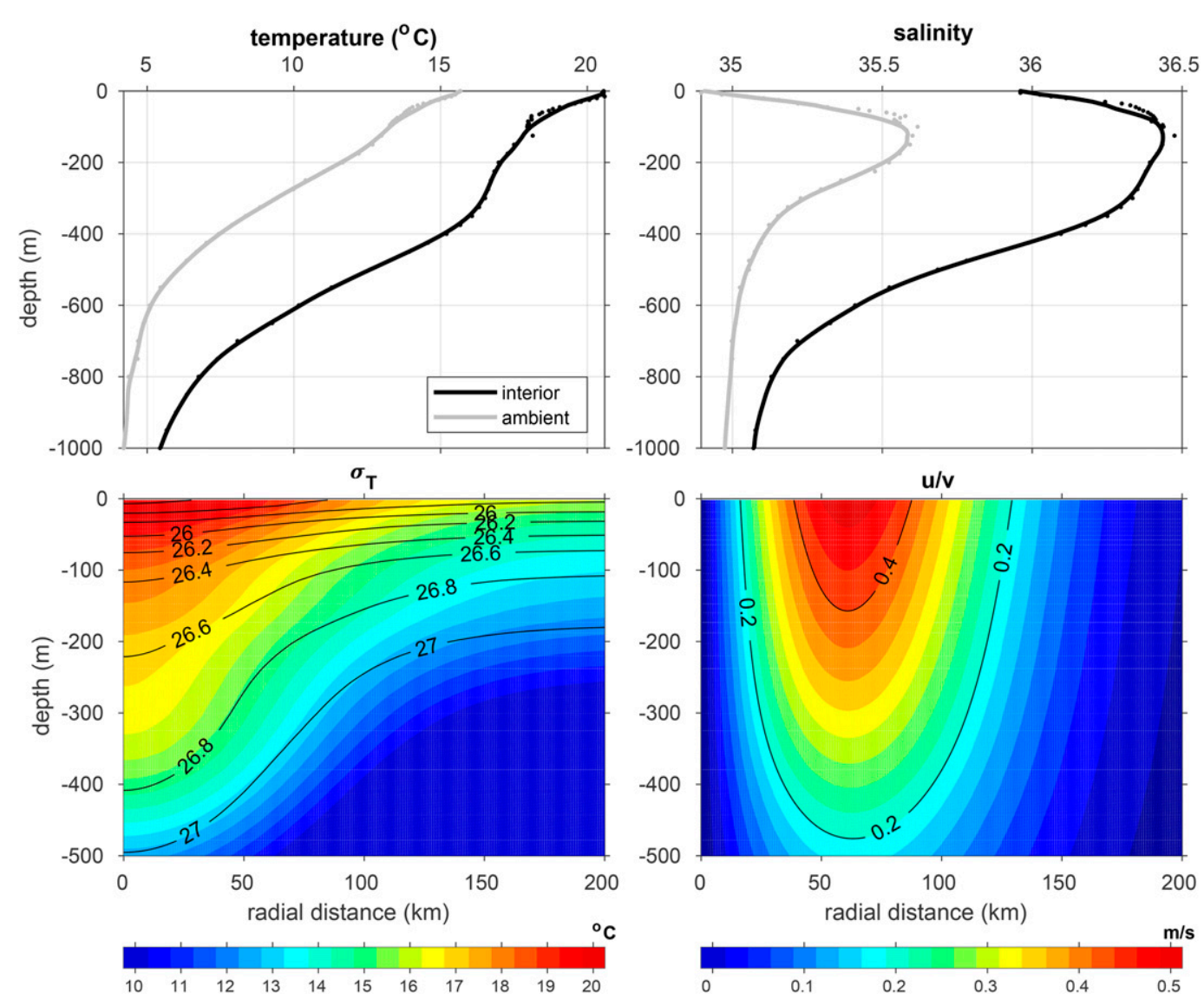

FIG. 1. Initial condition of the idealized warm core ring. (top) Temperature and salinity profiles in the center of the ring (black) and outside of the ring (gray). Dots represent the original data points, and solid curves represent smoothed profiles used in the model. (bottom) Sectional view of the potential density ( $\sigma_{T}$ in contours; colors represent temperature) and azimuthal velocity.

experiments below. This has been confirmed with sensitivity experiments using a $2 \mathrm{~m}^{2} \mathrm{~s}^{-1}$ Laplacian viscosity, a $1.25 \times 10^{5} \mathrm{~m}^{4} \mathrm{~s}^{-1}$ biharmonic viscosity based on a conversion from Laplacian to biharmonic viscosity $B=$ $A\left(\Delta^{2} / 8\right)$, where $B$ is the biharmonic viscosity (Griffies and Hallberg 2000), and Smagorinsky viscosity with Smagorinsky coefficient of 0.1 .

The initial condition is derived based on the historical observations from the Warm Core Ring Program (Schink et al. 1982; also section 2a). The temperature/salinity field is constructed using a profile in the center of the eddy and a climatological profile outside of the eddy assuming Gaussian distribution (e.g., McGillicuddy 2015), such that

$$
\begin{aligned}
& T(r, z)=T_{\text {out }}(z)+\left[T_{\text {in }}(z)-T_{\text {out }}(z)\right] \exp \left(-\frac{r^{2}}{r_{0}^{2}}\right), \\
& S(r, z)=S_{\text {out }}(z)+\left[S_{\text {in }}(z)-S_{\text {out }}(z)\right] \exp \left(-\frac{r^{2}}{r_{0}^{2}}\right) .
\end{aligned}
$$

Here subscript "in" and "out" denote profiles inside and outside of the ring, and $r_{0}$ is the radius ${ }^{1}$ of the ring, which is $100 \mathrm{~km}$, representative of the spatial scale of Gulf Stream warm core rings (e.g., Flierl 1979; Olson 1991). Using a smaller radius would produce sharper horizontal density gradients and stronger vertical motions, but does not affect the discussions of the main results in sections 3 and 4 . The 75 hydrographic profiles span 1981-82 but are mostly sampled in the warmer seasons from spring to fall, and thus the results in this study should be interpreted with this targeted time frame in mind. Water mass in the center of the ring is both warmer and saltier than the ambient slope water, with a noticeable subsurface warm/salty signal (Fig. 1). The difference in hydrography decreases with depth

\footnotetext{
${ }^{1}$ The definition of radius varies in the literature. The radius defined based on the maximum azimuthal velocity is typically smaller than that defined based on where isopycnals level out.
} 
TABLE 1. Configurations of the numerical experiments.

\begin{tabular}{lcccccc}
\hline \hline & $\begin{array}{c}\text { Viscosity } \\
\left(\mathrm{m}^{2} \mathrm{~s}^{-1}\right)\end{array}$ & $\begin{array}{c}\text { Wind speed } \\
\left(\mathrm{m} \mathrm{s}^{-1}\right)\end{array}$ & $\begin{array}{c}\text { Wind direction } \\
\text { (rotation period; } \mathrm{h})\end{array}$ & $\begin{array}{c}\text { Net heat flux } \\
\left(\mathrm{W} \mathrm{m}^{-2}\right)\end{array}$ & Wind stress formula & Wind stress calculation \\
\hline NF & 1 & 0 & - & 0 & - & - \\
VISC & 100 & 0 & - & 0 & - & - \\
WIND & 1 & 7.5 & 64 & 0 & Large and Pond 1981 & $U_{a}$ \\
RWIND & 1 & 7.5 & 64 & 0 & Large and Pond 1981 & $U_{a}-U_{o}$ \\
REAL & 1 & Realistic & Realistic & Realistic & COARE 3.0 (Fairall et al. 2003) & $U_{a}-U_{o}$ \\
\hline
\end{tabular}

toward $1000 \mathrm{~m}$. Nonlinear equation of state was used to calculate the initial density field (Fig. 1). The sloping isopycnals with weaker stratification in the center of the ring indicates the temperature field dominates the density structure. The initial 3D velocity field was computed assuming geostrophic balance. Additional calculation using cyclogeostrophic balance, in which the centrifugal acceleration was also considered in addition to the geostrophic balance, does not produce a difference beyond the initial time steps as the cyclogeostrophic balance only adds a small correction, mostly near the edge of the ring, to the geostrophic velocity. To minimize the generation of transient internal waves during the initial Rossby adjustment, we reinitialize all model simulations from one snapshot from the unforced spindown simulation, at which point, the wave signals have significantly diminished. It is worth noting that the initial condition here is constructed based on observed temperature and salinity profiles, and thus represents a more realistic state in comparison to purely idealized profiles. This allows us to discuss the vertical velocity and nutrient delivery (section 4) in a more realistic context.

We design numerical experiments with various forcing conditions to isolate and compare different processes involved with the vertical velocity (Table 1). In the first set of experiments, the decay of a warm core ring with lateral and bottom friction is considered. The experiment NF is prescribed with realistic horizontal viscosity, and the experiment VISC is prescribed with large viscosity. To understand the wind-forced vertical motions, we conduct experiment WIND in which only wind stress is prescribed with idealized wind forcing conditions. A comparative experiment RWIND is the same as experiment WIND except wind stress is calculated with the relative wind speed to the ocean surface. A more realistic forcing scenario is considered in experiment REAL, in which climatological wind during spring and early summer is prescribed and the wind stress is calculated using the relative wind speed. More details on the experiments can be found below in section 3 .

To minimize the interference of near-inertial wave motions, a temporal averaging over two inertial periods $(\sim 1.5$ days $)$ is applied to all fields in the output. This procedure is based on the fact that the wave signals peaked at the Coriolis frequency in the spectrum analysis (not shown) and is applied during the model stepping. To confirm the effectiveness of this procedure, an additional experiment REAL with a 3-hourly output interval is conducted, and 48-h low-pass filtering is applied to the 3-hourly vertical velocity field. The low-pass-filtered instantaneous vertical velocity, particularly its spatial structure, matches very well with the averaged vertical velocity over two inertial periods, which justifies the averaging procedure. We choose averaging every two inertial periods over low-pass filtering of the high-frequency output because low-pass filtering cannot be applied to the highly nonlinear diagnostic terms [in Eqs. (4) and (5), see section 2c below]. Doing so will violate the budget closure and prevent us from diagnosing the vertical velocity from the primitive equation model using Eqs. (4) and (5), one important part of this study.

\section{c. Vertical velocity diagnosis}

To understand the material transport and physicalbiological interactions in mesoscale eddies, it is key to elucidate the characteristics of the vertical velocity field. Below, we attempt to interpret the vertical velocity using two different approaches.

\section{1) A generalized, DiABATIC OMEgA EQUATION}

The omega equation has been widely used to infer mesoscale vertical velocity in oceanic applications (e.g., Tintoré et al. 1991; Pollard and Regier 1992; Shearman et al. 2000; Pascual et al. 2015; Barceló-Llull et al. 2017). The omega equation used here is a generalized, diabatic version, which in comparison to quasigeostrophic or semigeostrophic formulation, is more accurate and is suitable for applications in a wider parameter space (Viúdez et al. 1996; Pallàs-Sanz and Viúdez 2005; Pallàs-Sanz et al. 2010). To aid discussion, we provide a brief review of the omega equation used here.

In the quasigeostrophic (QG) framework, the omega equation can be derived in the $\mathbf{Q}$-vector form (Hoskins et al. 1978):

$$
N^{2} \nabla_{h} w+f^{2} w_{z z}=2 \nabla_{h} \cdot \mathbf{Q}^{g},
$$

where $N^{2}(z)=-\rho_{0}^{-1} g \rho_{z}$ is the buoyancy frequency, $w$ is the vertical velocity to be solved, $f$ is the Coriolis 
parameter, and $\mathbf{Q}^{g} \equiv \nabla_{h} \mathbf{u}^{g} \cdot \nabla_{h} \varrho$ is the geostrophic frontogenetical term or geostrophic deformation term, with $\mathbf{u}^{g}$ being geostrophic velocity vector and $\varrho \equiv \rho_{0}^{-1} \rho g$ being buoyancy.

For large Rossby number scenarios, a generalized omega equation with higher-order accuracy for hydrostatic, inviscid, isentropic, and Boussinesq flow on an $f$ plane is derived as (Viúdez et al. 1996; Pallàs-Sanz and Viúdez 2005)

$$
\begin{aligned}
\frac{d \zeta_{z}^{\prime}}{d t}= & -f^{-1} \nabla_{h} \cdot\left(2 \mathbf{Q}_{h}+\varrho_{z} \nabla_{h} w\right)+(f+\zeta) w_{z z} \\
& +\zeta_{p h z}^{\prime} \cdot \nabla_{h} w-\zeta_{p h}^{\prime} \cdot \nabla_{h}^{2} \mathbf{u}_{h},
\end{aligned}
$$

where $\zeta_{z}^{\prime}=v_{x}^{\prime}-u_{y}^{\prime}$ is the vertical derivative of the ageostrophic vorticity, $\mathbf{Q}_{h} \equiv \nabla_{h} \mathbf{u}_{h} \cdot \nabla_{h} \varrho$ is the $\mathbf{Q}$ vector that includes both geostrophic and ageostrophic parts, $\zeta_{p h}^{\prime}=\left(-v_{z}^{\prime}, u_{z}^{\prime}\right)$ is the horizontal ageostrophic pseudovorticity, and $\zeta_{p h z}^{\prime}$ is its vertical derivative. If one neglects (i) the material rate of change of $\zeta_{z}^{\prime}$, (ii) nondiagnostic terms $\zeta_{p h z}^{\prime} \cdot \nabla_{h} w$ and $\nabla_{h} \varrho_{z} \cdot \nabla_{h} w$, and (iii) the horizontal change of $\varrho$, the generalized omega Eq. (2) is approximated as

$$
N^{2} \nabla_{h}^{2} w+f(f+\zeta) w_{z z}=2 \nabla_{h} \cdot \mathbf{Q}_{h}+f \zeta_{p h}^{\prime} \cdot \nabla_{h}^{2} \mathbf{u}_{h} .
$$

The first term on the right-hand side of Eq. (3) is referred to as total deformation $S_{\mathrm{DEF}}$, which includes both the geostrophic and ageostrophic deformation. The second term is the ageostrophic advection $S_{\mathrm{ADV}}$, although $S_{\mathrm{DEF}}$ can also be related to the advection of vertical vorticity by the geostrophic shear (Pallàs-Sanz et al. 2010).

If one considers the vertical mixing of buoyancy and momentum, Eq. (3) can be further extended:

$$
\begin{aligned}
N^{2} \nabla_{h}^{2} w+f(f+\zeta) w_{z z}= & 2 \nabla_{h} \cdot \mathbf{Q}_{h}+f \zeta_{p h}^{\prime} \cdot \nabla_{h}^{2} \mathbf{u}_{h} \\
& +f\left(\zeta_{p h} \cdot \nabla_{h} A_{v}-A_{v} \zeta_{z}\right)_{z z} \\
& -\left[\nabla_{h}^{2}\left(K_{v} \varrho_{z}\right)\right]_{z}
\end{aligned}
$$

where $A_{v}$ and $K_{v}$ are vertical turbulent viscosity and diffusivity, respectively. The additional two terms in Eq. (4) are referred to as $S_{\mathrm{MOM}}$ and $S_{\mathrm{BUO}}$, respectively. Equation (4) is an elliptic equation of $w$ and can be solved using an iterative relaxation method (Pallàs-Sanz and Viúdez 2005; Pallàs-Sanz et al. 2010).

\section{2) A semidiagnostic Vorticity EQUATION}

Another way to understand the structure of the vertical velocity is based on the flow divergence method (Koszalka et al. 2009). The idea is to infer vertical velocity using the horizontal velocity components assuming continuity. Starting with the vorticity equation, the vertical velocity can be retrieved:

$$
\begin{aligned}
& w(x, y, z)=\underbrace{\frac{D \eta}{D t}}_{\text {free surface (FS) }} \underbrace{-\int_{z}^{\eta} \frac{1}{\zeta+f} \frac{\partial \zeta}{\partial t} d z}_{\text {vorticity change (RATE) }} \underbrace{-\int_{z}^{\eta} \frac{1}{\zeta+f} u \cdot \nabla \zeta d z}_{\text {nonlinear vorticity advection (NL) }}-\underbrace{\int_{z}^{\eta} \frac{1}{\zeta+f}\left(\frac{\partial v}{\partial z} \frac{\partial w}{\partial x}-\frac{\partial u}{\partial z} \frac{\partial w}{\partial y}\right) d z}_{\text {tilting (TI) }} \\
& \underbrace{-\int_{z}^{\eta} \frac{1}{\zeta+f}\left[\frac{\partial}{\partial y}\left(-\frac{1}{\rho} \frac{\partial p}{\partial x}\right)-\frac{\partial}{\partial x}\left(-\frac{1}{\rho} \frac{\partial p}{\partial y}\right)\right] d z}_{\text {baroclinic (BC) }} \underbrace{-\int_{z}^{\eta} \frac{1}{\zeta+f}\left[-A_{H}\left(\frac{\partial^{4}}{\partial x^{4}}+\frac{\partial^{4}}{\partial y^{4}}\right)\right] \zeta d z}_{\text {horizontal mixing (HM) }} \\
& \underbrace{-\int_{z}^{\eta} \frac{1}{\zeta+f}\left[\frac{\partial}{\partial y} \frac{\partial}{\partial z}\left(K_{v} \frac{\partial u}{\partial z}\right)-\frac{\partial}{\partial x} \frac{\partial}{\partial z}\left(K_{v} \frac{\partial v}{\partial z}\right)\right] d z}_{\text {vertical mixing }(\mathrm{VM})}
\end{aligned}
$$

The derivation is done by cross differentiating the horizontal momentum equations. Equation (5) is similar to Eq. (1) in (Koszalka et al. 2009) but is different in that the terms are not split and surface wind forcing is included in the vertical mixing term (VM). As a result, we do not separately define a stretching term and wind stress term as was done in (Koszalka et al. 2009). Note that Eq. (5) is a semidiagnostic expression about $w$, as $w$ appears on the right-hand side too. Nevertheless, it can be used to estimate the contributions of each term to $w$. Also, it is worth noting that the numerical model, omega equation and the vorticity equation are all considered for an $f$ plane, which allows the results to be directly compared against each other.

\section{Vertical velocity in warm core rings}

\section{a. Frictional decay}

The concept of frictional decay of Gulf Stream warm core rings is conceived by Flierl and Mied (1985) based on the earlier work of spindown of mesoscale eddies (Molinari 1970; Scemitz and Vastano 1975). Using an 

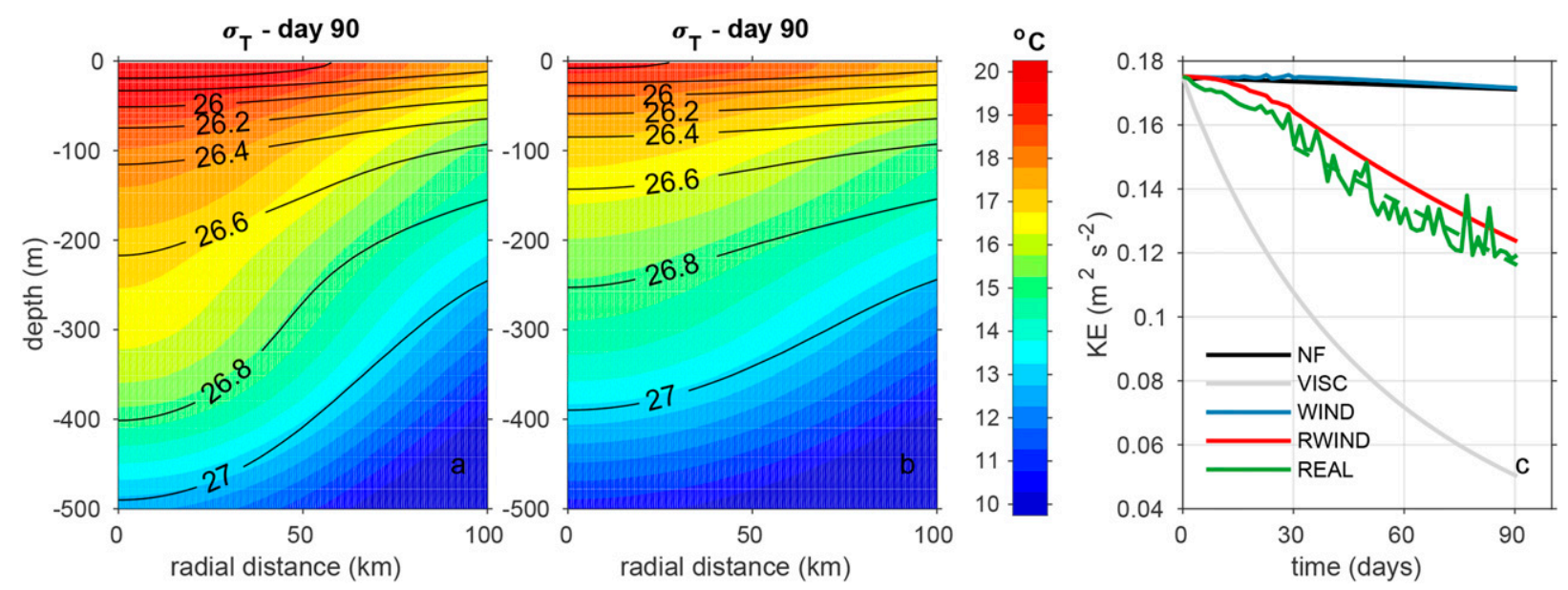

FIG. 2. Azimuthally averaged cross section of temperature (color) and density (contours) after 90 days from initialization. (a) Control experiment (NF) with $1 \mathrm{~m}^{2} \mathrm{~s}^{-1}$ viscosity. (b) Large viscosity experiment (VISC) with $100 \mathrm{~m}^{2} \mathrm{~s}^{-1}$ viscosity. (c) Average surface kinetic energy within the radius of $100 \mathrm{~km}$. The green dashed line represents the linear trend from day 30 to 90 for experiment REAL.

analytical quasigeostrophic model and a numerical model, Flierl and Mied (1985) show that the lateral mixing of momentum is effective in spinning down the warm core ring and inducing upwelling in the core when Prandtl number $P_{r}=\nu_{h} / k_{h}$ is larger than 1 , where $\nu_{h}$ and $k_{h}$ are horizontal viscosity and diffusivity, respectively. The opposite is found when $P_{r}$ is less than 1, that is, downwelling in the center of the warm core ring. Within reasonable parameter ranges, Flierl and Mied (1985) estimate an upwelling velocity of $\sim 1 \mathrm{~m} \mathrm{day}^{-1}$, consistent with values reported from observations of warm core ring 82B (Olson et al. 1985). The response of the marine ecosystem to this decay process is further investigated by Franks et al. (1986), who shows that phytoplankton grow on nutrient injected into the euphotic zone as the depressed isopycnals rebound to the surface, which is associated with vertical advection and diapycnal mixing. Because of the convoluted nature of the vertical processes within mesoscale eddies, it is necessary to isolate the frictional decay from other processes so that a baseline can be established.

Based on a realistic horizontal viscosity of $1 \mathrm{~m}^{2} \mathrm{~s}^{-1}$, the warm core ring in experiment NF, however, shows no sign of decay after 90 days (Fig. 2a). In comparison to the initial condition (Fig. 1c), the change of isopycnals is negligible. Although the bottom friction is also prescribed, it obviously does not impact the upper water column. To demonstrate the effect of horizontal mixing of momentum, we further apply in the experiment VISC a horizontal viscosity of $100 \mathrm{~m}^{2} \mathrm{~s}^{-1}$, which is two orders of magnitude larger than the reasonable viscosity for the $1-\mathrm{km}$ scale considered here. This artificially high viscosity is required for frictional decay alone to be noticeable (Fig. 2b). The isotherms (isopycnals) have significantly risen from the initial state, with decreasing (increasing) temperature (density) especially in the core of the ring. For example, the $27 \mathrm{~kg} \mathrm{~m}^{-3}$ isopycnal near the ring center rose from $\sim 500 \mathrm{~m}$ on day 1 to $\sim 400 \mathrm{~m}$ on day 90 , representing an equivalent upwelling velocity of $\sim 1 \mathrm{~m} \mathrm{day}^{-1}$, consistent with the value reported earlier (Flierl and Mied 1985; Olson et al. 1985; Franks et al. 1986). The upward movement of isosurfaces is presumably caused by the diapycnal mixing as there is no surface heat flux or momentum forcing acting to change the water property or induce water mass convergence/divergence. It is notable that the rise of deeper isopycnals is more significant near the center of the ring. This is because the horizontal viscosity has a larger component in the diapycnal direction as the slope of the isopycnals is greater there.

The diagnostics of vertical velocity during inertial period 41-42 further confirms this enhanced pattern in the deeper water column in the ring center (Fig. 3). The vertical velocity induced by horizontal mixing term HM is larger than $1 \mathrm{~m} \mathrm{day}^{-1}$, at $500 \mathrm{~m}$ in the ring center. The vertical velocity induced by the change of vorticity (RATE) can be described as downwelling of $-0.8 \mathrm{~m}$ day $^{-1}$, which is a result of the decreased vorticity magnitude during the decay process [Eq. (5)]. The residual of HM and RATE is the total vertical velocity, which is slightly larger than $0.2 \mathrm{~m} \mathrm{day}^{-1}$ at $500 \mathrm{~m}$. In addition to the upwelling pattern in the center of the ring, weak downwelling around the periphery of the ring is also noticeable. In combination, the upwelling and downwelling constitute two secondary circulation cells (in the sense of $2 \mathrm{D}$ cross section) conserving water mass in the vertical plane.

Although the result is based on a large horizontal viscosity, the magnitude of upwelling and the structure 

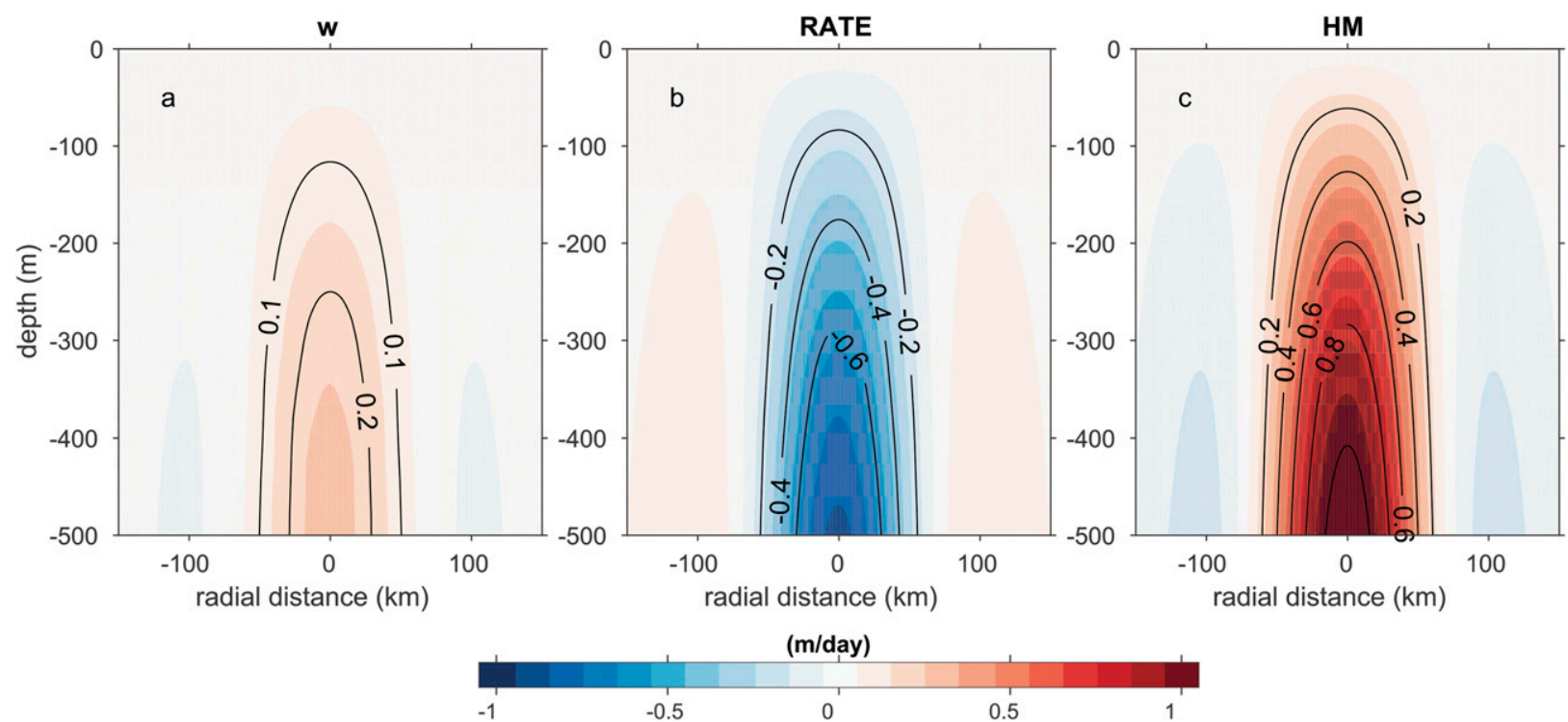

FIG. 3. Vertical velocity and its diagnostic terms during inertial periods $41-42$ since initialization from large viscosity experiment (VISC) (a) average vertical velocity, (b) vertical velocity contributed by time rate of change of relative vorticity, and (c) horizontal mixing of momentum. Only the leading terms in Eq. (5) are shown.

of the secondary circulation cell is consistent with Flierl and Mied (1985). As will be discussed in the following, other processes such as Ekman pumping, can produce vertical velocity with quite similar characteristics, posing the question of whether or not frictional decay alone is an effective mechanism for sustaining primary production in the real ocean. Indeed, the evolution of the surface kinetic energy when wind forcing is imposed reveals a significant rate of decay, much larger than what friction $\left(1 \mathrm{~m}^{2} \mathrm{~s}^{-1}\right)$ alone could produce (Fig. $2 \mathrm{c}$ ). The decay rate when a large viscosity is considered is comparable to that when representative wind forcing is imposed, with the consideration of relative wind speed to the ocean current. It is also worth noting that the above results are based on Prandtl number 1. As mentioned in section $2 b$, we also conducted a sensitivity experiment using Prandtl number 2 and did not find noticeable differences in the vertical velocity field. In both cases, upwelling is produced in the ring center, which is different from the findings in Flierl and Mied (1985).

\section{b. Wind-forced vertical motions}

When considering both the planetary vorticity and the relative vorticity in calculating Ekman transport, upwelling/downwelling will arise as a result of horizontal gradient of relative vorticity (Stern 1965; Niiler 1969). This has been called vorticity gradient-induced Ekman pumping (Gaube et al. 2015) or simply nonlinear Ekman pumping. In the meantime, consideration of the relative speed between the wind and current (instead of the wind speed alone) in the calculation of wind stress can yield mesoscale variations in Ekman divergence. The resulted Ekman pumping, which is referred to as currentinduced or linear Ekman pumping, produces upwelling within anticyclones and downwelling within cyclones (Dewar and Flierl 1987; Martin and Richards 2001). Considering both vorticity and wind stress contribution, the total Ekman pumping can be formulated as follows (Stern 1965):

$$
\begin{aligned}
w \approx & \nabla \cdot \frac{\boldsymbol{\tau} \times \mathbf{k}}{\rho_{0}(f+\zeta)}=\underbrace{\frac{1}{\rho_{0}(f+\zeta)}\left(\frac{\partial \tau_{y}}{\partial x}-\frac{\partial \tau_{x}}{\partial y}\right)}_{w_{c}} \\
& +\underbrace{\frac{1}{\rho_{0}(f+\zeta)^{2}}\left(\tau_{x} \frac{\partial \zeta}{\partial y}-\tau_{y} \frac{\partial \zeta}{\partial x}\right)}_{w_{\zeta}} .
\end{aligned}
$$

The first term exists because of the wind stress curl and is commonly referred to as the linear Ekman term in the literature, although being nonlinear. We therefore adopt the terminology put forth in Gaube et al. (2015) and will refer to this as current-induced Ekman pumping $w_{c}$. The second term arises because of the horizontal gradient of relative vorticity and has been referred to as the nonlinear Ekman term, but for the reasons described above, we will refer to this term as the vorticity gradient-induced Ekman pumping $w_{\zeta}$. This term can also be written in terms of advection of the vertical component of the absolute vorticity by the classic linear Ekman transport $\mathbf{M}_{L}$ : 


$$
w_{\zeta}=\frac{f}{(f+\zeta)^{2}} \underbrace{\left(\frac{\boldsymbol{\tau} \times \mathbf{k}}{\rho_{0} f}\right)}_{\mathbf{M}_{L}} \cdot \nabla_{h}(f+\zeta) .
$$

Hence, the vorticity gradient-induced nonlinear Ekman pumping can be interpreted in a similar manner as the forcing term for vertical velocity in the generalized omega equation, that is, the advection of vertical vorticity by the vertical shear velocity (Pallàs-Sanz and Viúdez 2005).

An extension of the nonlinear Ekman transport is considered for flows with curvature and high Rossby number by Wenegrat and Thomas (2017). With higherorder terms in Rossby number included, the magnitude of Ekman pumping is reduced in anticyclones, although the dipolar spatial pattern remains the same (Wenegrat and Thomas 2017). It is outside the scope of the current work to evaluate different formulations of Ekman pumping and the $w_{c}$ and $w_{\zeta}$ considered here should be interpreted based on the Stern (1965) formulation.

Despite numerous studies, the understanding of the roles of current-induced and vorticity gradient-induced Ekman pumping in supporting the upper-ocean ecosystem across different temporal and spatial scales is still inadequate. From an observational standpoint, the Ekman velocities formulated in Eq. (6) cannot be directly observed and can only be estimated from other measurable quantities at ocean surface. From a numerical modeling perspective, the Ekman pumping is often embedded in the vertical velocity field, which inevitably contains signals from other processes, for example, larger-scale heaving of isopycnals and internal waves, and thus is not always traceable. In this section, we examine numerical experiments with various forcing conditions to examine the vertical motions in the WCRs.

\section{1) IDEALIZED WIND FORCING}

Two numerical experiments are designed to compare $w_{\zeta}$ and $w_{c}$ in WCRs with idealized wind forcing. The wind speed is chosen to be $7.5 \mathrm{~m} \mathrm{~s}^{-1}$, representative of wind conditions in spring in the northwest Atlantic slope region based on the ERA-Interim dataset (Berrisford et al. 2011). The wind direction rotates clockwise with a period of $64 \mathrm{~h}$. In comparison to constant wind direction, the rotating wind can reduce the distortion of the ring and the sea level setup in one particular direction. We note that the configuration of the forcing field needs to satisfy the goal of the idealized wind experiments, which is to capture and compare $w_{\zeta}$ and $w_{c}$. The choice of 64-h rotation is effective for our purpose and is consistent with that used in McGillicuddy (2015). In addition, to minimize the generation of near-inertial internal waves, a ramp-up period of 30 days is implemented in such a fashion that the wind speed remains zero in the first 8 days and ramps up linearly to $7.5 \mathrm{~m} \mathrm{~s}^{-1}$ after 30 days. This procedure is important, as internal waves produced by both the initial adjustment and wind forcing would overwhelm the vertical velocity field without this ramp-up treatment. In the experiment WIND, the wind stress is calculated using the formula by Large and Pond (1981) without considering the relative wind speed to the ocean. In this case, only the nonlinear Ekman term is represented. In another experiment RWIND, the relative wind speed is considered when calculating the wind stress, that is,

$$
\tau=\rho_{\text {air }} C_{d}\left(\mathbf{u}_{a}-\mathbf{u}_{o}\right)\left|\mathbf{u}_{a}-\mathbf{u}_{o}\right|,
$$

where $\rho_{\text {air }}$ is the density of air, $C_{d}$ is the drag coefficient, $\mathbf{u}_{a}$ is the wind at $10 \mathrm{~m}$ above the sea surface, and $\mathbf{u}_{o}$ is the ocean surface velocity. Here $C_{d}$ is defined based on the method in Large and Pond (1981). In this case, both the $w_{\zeta}$ and $w_{c}$ terms are included. In both WIND and RWIND experiment, the net surface heat flux is zero so only wind-forced motions are considered.

The vertical velocity at $20 \mathrm{~m}$ depicts the pattern of $w_{\zeta}$ in an anticyclone (Fig. 4a). Because of the negative vorticity within the ring, Ekman transport inside the ring is larger compared to that outside the ring. The lateral difference in Ekman transport generates an upwelling/downwelling center, the location of which depends on the wind direction. The vertical velocity is $\sim 0.5 \mathrm{~m} \mathrm{day}^{-1}$ for a wind stress of $0.08 \mathrm{~N} \mathrm{~m}^{-2}$ on day 36. Theoretically, the Ekman pumping velocity is a result of Ekman transport divergence/convergence and exists just below the Ekman layer. Without other processes, the upwelling and downwelling cells extend up to 1000-m depth, well beyond the surface boundary layer (Fig. 4b). This could explain how vertical fluxes generated at the base of the Ekman layer can influence the distribution of tracers below (e.g., Pietri et al. 2013). In combination with the surface Ekman drift, this will produce a lateral secondary circulation from one side of the ring to the other side (Fig. 5b).

When the relative wind is considered, the dipolar pattern associated with $w_{\zeta}$ is modified (Figs. $4 \mathrm{c}, \mathrm{d}$ ) with additional upwelling in the center of the anticyclonic ring due to Ekman divergence. Specifically, the anticyclonic ring modifies the otherwise uniform wind stress, producing a positive wind stress curl (Fig. 4e), which further induces upwelling in the center of the ring (Fig. 4f).

Because of the existence of unbalanced wave motions, the spatial pattern of vertical velocities is slightly different from the exact $w_{\zeta}$ and $w_{c}$ based on idealized calculations (McGillicuddy et al. 2008; Gaube et al. 2015; Wenegrat and Thomas 2017). The relative magnitude of 

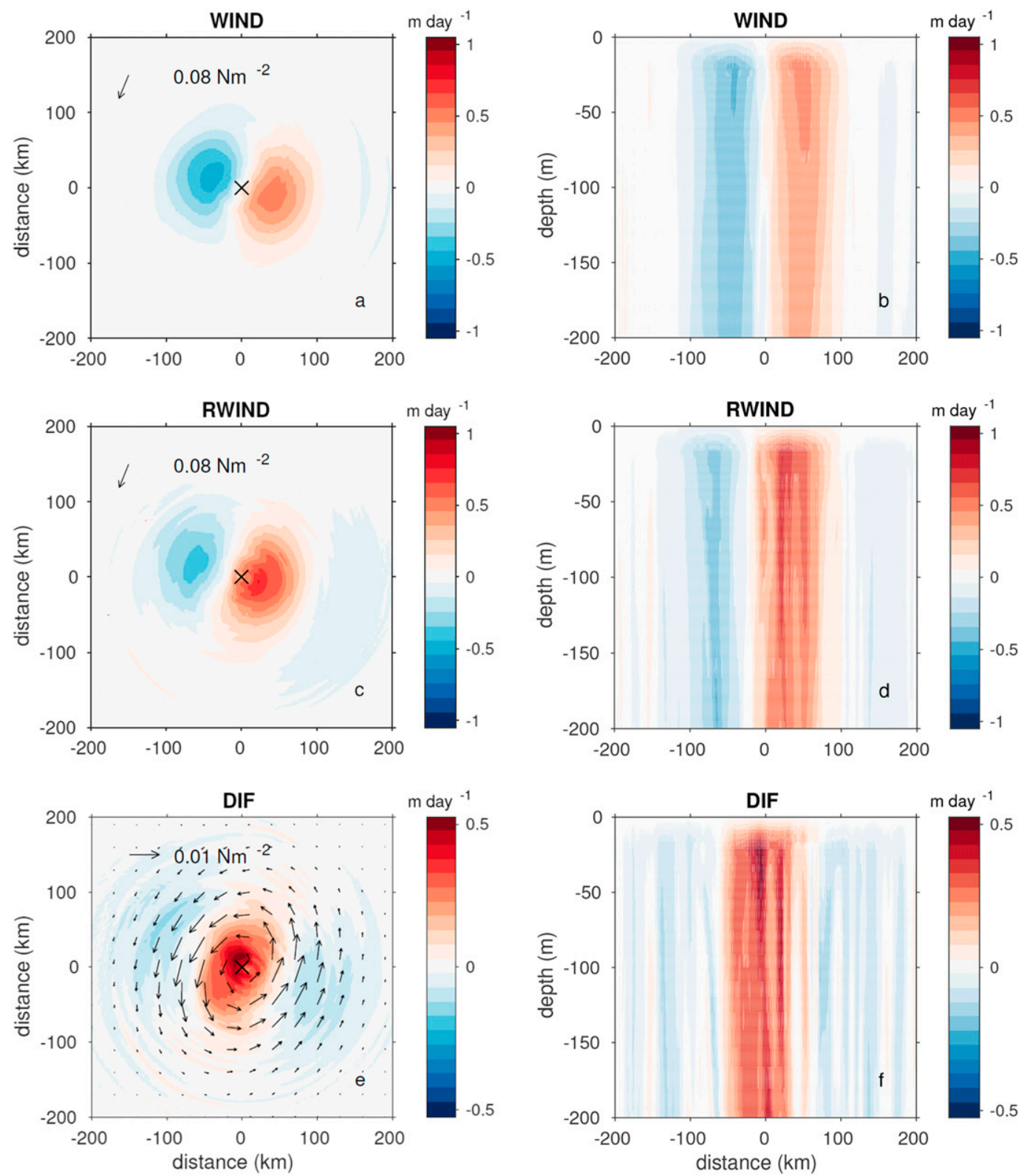

FIG. 4. Instantaneous vertical velocity on day 36 from experiment (a),(b) WIND, (c),(d) experiment RWIND, and (e),(f) differences between the two experiments. Note the changes in color scale. (left) Plan view at $20 \mathrm{~m}$. (right) Zonal sectional view across the core. The cross marks the center of the ring.

vorticity gradient-induced and current-induced Ekman pumping can be scaled as

$$
\begin{aligned}
\frac{W_{\zeta}}{W_{c}} & \approx \frac{-\tau_{y} \frac{\partial \zeta}{\partial x}}{(f+\zeta) \frac{\partial \tau}{\partial x}} \sim \frac{1}{f_{0}+\zeta_{0}} \frac{-\tau_{0} \frac{\zeta_{0}}{R}}{\frac{2 \tau_{0} \frac{\Delta U_{o}}{U_{a}}}{2 R}}=\frac{-\zeta_{0}}{f+\zeta_{0}} \frac{U_{a}}{2 U_{o}} \\
& =\frac{-R_{o}^{*}}{1+R_{o}^{*}} \frac{U_{a}}{2 U_{o}},
\end{aligned}
$$

where $R_{o}^{*}$ is Rossby number, negative for anticyclones and positive for cyclones, $U_{a}$ is wind speed, and $U_{o}$ is the ring's azimuthal velocity. Here, the derivation is based on the meridional component, and the wind stress difference due to the consideration of relative wind [Eq. (8)] is $2 \tau_{0}\left(\Delta U_{o} / U_{a}\right)$. Note this is similar but different from the scaling by Mahadevan et al. (2008), which is $R_{o}\left(U_{a} / U_{o}\right)$. For a $R_{o}^{*}$ of $-0.3, U_{a}$ of 7.5 , and $U_{o}$ of $0.5, w_{\zeta}$ is about 3 times $w_{c}$. This is consistent with the indirect comparison of the instantaneous vertical velocities in 

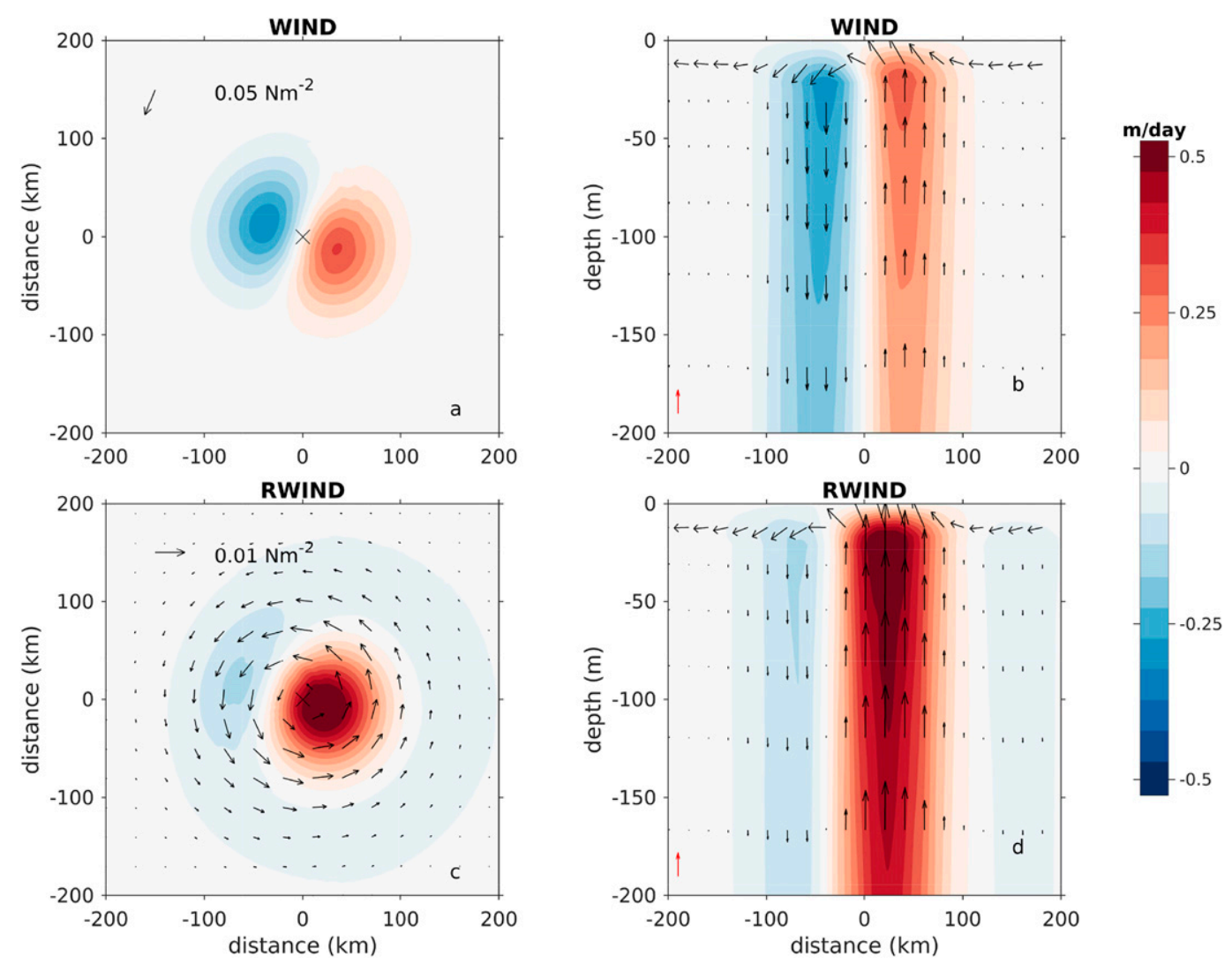

FIG. 5. Mean vertical velocity during inertial periods 47-48 (around day 36) from experiment (a),(b) WIND and (c),(d) RWIND (left) Plan view at $20 \mathrm{~m}$. (right) Zonal sectional view across the core. The vertical velocities in (b) and (d) are scaled with $10 \times 10^{4}$. The red arrow denotes a vertical velocity of $0.2 \mathrm{~m} \mathrm{day}^{-1}$ and a horizontal velocity of $2 \mathrm{~km} \mathrm{day}^{-1}$.

Fig. 4. However, on the time scale of days, the scale at which vertical transport begins to be important for the upper-ocean ecosystem, $w_{\zeta}$ is no longer much larger than $w_{c}$ (Fig. 5). The total Ekman pumping (Figs. 5c,d) is much larger than $w_{\zeta}$ (Figs. 5a,b) during the inertial period of 47-48, indicating $w_{c}$ is comparable with $w_{\zeta}$. This is because the locations of the dipolar pattern of $w_{\zeta}$ changes with the wind direction and the monopolar pattern of $w_{c}$ does not. With varying wind direction, the dipolar cells can partially cancel each other. This time-scaledependence nature will be further discussed below.

The dynamics associated with $w_{\zeta}$ and $w_{c}$ can be compared from the diagnostic analysis of vertical velocity based on Eq. (5). For $w_{\zeta}$, the dipolar vertical velocity is primarily determined by the vorticity change (RATE) and nonlinear vorticity advection (NL), in which the horizontal component is clearly dominant (Fig. 6). This is due to the Ekman transport in the upper water column $(\sim 20 \mathrm{~m})$. Specifically, the northeasterly wind during inertial periods 47-48 drives northwestward Ekman transport (Figs. 5a,b), which increases the vorticity on the downwind flank (where azimuthal velocity is in the direction of the wind, southeast flank in Fig. 5a) of the ring by transporting larger vorticity (less negative vorticity). Similarly, the Ekman transport of negative vorticity decreases the vorticity at the upwind flank. The advection of vorticity is reflected in the vorticity change term (Fig. 6c). Note the RATE term is converted to vertical velocity term [see Eq. (5)] so the increasing vorticity is equivalent to downward motion and the decreased vorticity is equivalent to upward motion. The advection of vorticity and vorticity change do not exactly cancel each other, thus leading to the imbalance of vorticity, based on which vertical velocity arises $(\partial w / \partial z \neq 0$ and Fig. 6a). Because this is a departure from geostrophic balance, the combination of RATE and NL terms are also referred to as ageostrophic terms (Koszalka et al. 2009).

In comparison, the balance terms when we consider both current and vorticity gradient-induced Ekman dynamics are different. Although the horizontal advection of vorticity still operates, the upwelling in the center of the ring overwhelms the vorticity balance, leading to increased vorticity in the ring (less negative vorticity, Fig. 6f). The imbalance of vorticity due to the combination 

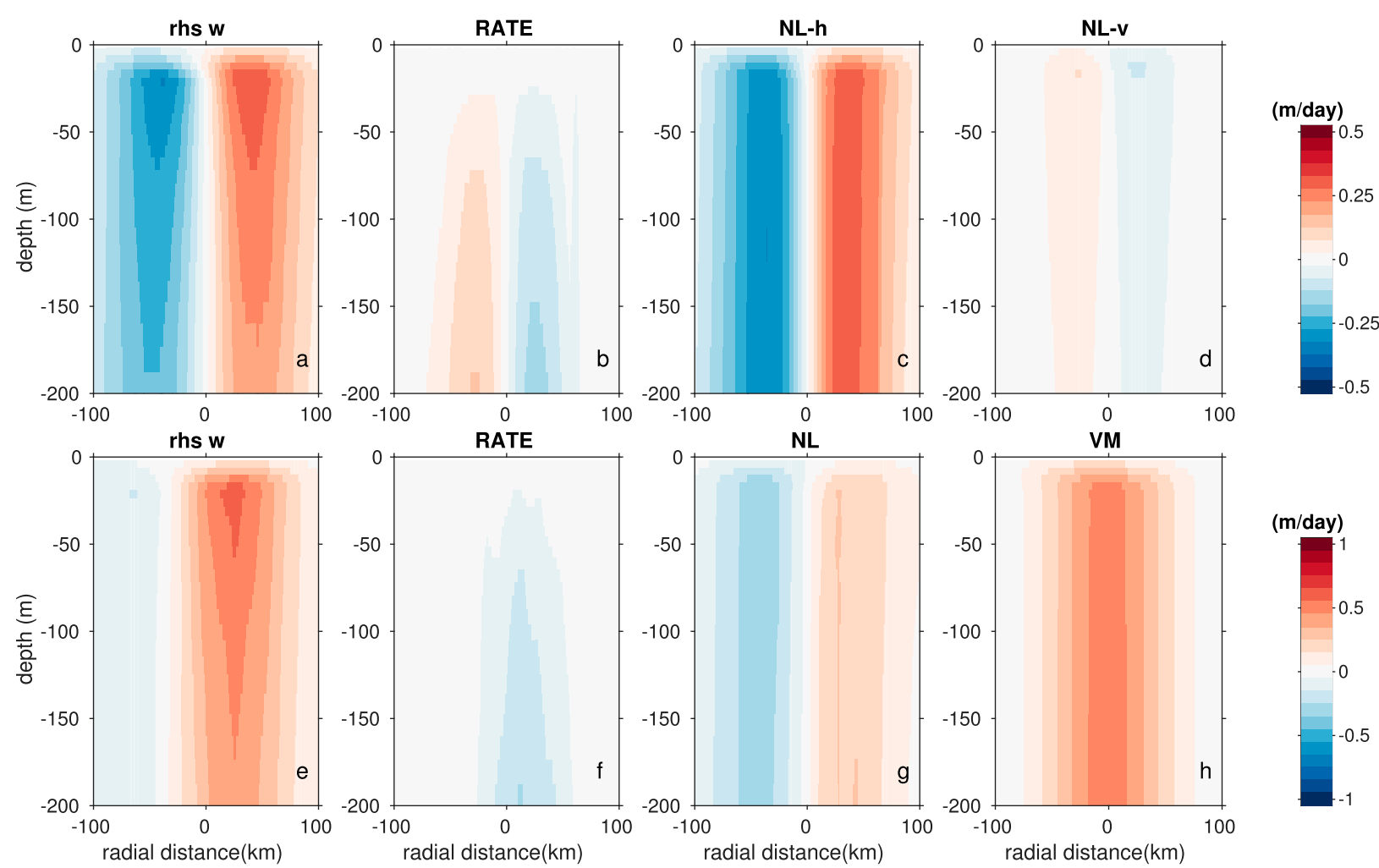

FIG. 6. Diagnostic terms of vertical velocity during initial periods 47-48 (around day 36) from experiment (top) WIND and (bottom) RWIND. (a),(e) Vertical velocity across the core calculated from the semidiagnostic equation [Eq. (5)] and contributions from (b),(f) time rate of change of relative vorticity, (c) horizontal advection of vorticity, (d) vertical advection of vorticity, (g) advection of vorticity (including both horizontal and vertical), and (h) vertical mixing of momentum. Only the leading terms in Eq. (5) are shown. Note the different color scale.

of horizontal and vertical advection shapes the structure of the vertical velocity field. It is worth clarifying that the local rate of vorticity change is surface intensified as expected with surface wind forcing. However, when converting to equivalent vertical velocity RATE, the vertical integral from depth to surface [see Eq. (5)] produces a bottomintensified pattern (Figs. 6b,f). Similarly, the advection of vorticity and Ekman divergence only exist in the upper water column, but the conversion to vertical velocity (NL and VM) based on the integral over the water column yields a uniform pattern in the vertical direction.

\section{2) REALISTIC WIND FORCING}

While $w_{\zeta}$ and $w_{c}$ have been characterized under idealized forcing conditions, further understanding of the vertical velocity under more realistic forcing conditions is necessary. In particular, the variability of vertical velocity over a typical lifespan of WCRs, a time scale meaningful for vertical nutrient delivery and ecosystem response, needs to be investigated. To do so, we apply realistic atmospheric forcing and consider both the nonlinear and linear Ekman processes, that is, relative wind to the ocean is used. The wind field is a 3-hourly climatological mean from 1992 to 2016 (Fig. 7). The constructed wind field may have averaged out some higher-frequency signals, but it is nevertheless representative of the realistic wind forcing conditions in the region. For this study, because we are interested in the spring-summertime of the year, the wind field is prescribed to start from April. Other atmospheric variables include radiation fluxes, cloud coverage, precipitation, surface air pressure, relative humidity, and temperature. Both wind stress and net air-sea heat flux are computed using a bulk flux formula COARE 3.0 (Fairall et al. 2003).

The vertical velocity at $50 \mathrm{~m}$ changes remarkably during the evolution of the ring. In the earlier stage of the ring, the vertical velocity is primarily determined by the total Ekman pumping (Fig. 8a), a pattern that is quite similar to the vertical velocity field forced under idealized winds (Fig. 5). Because both the wind speed and direction change over time, this simple pattern gradually disappears (Figs. 8b,c). Unlike the case with idealized wind, that is, constant magnitude and a $64-\mathrm{h}$ period, the vertical velocity field is dominated by near inertial wave motions. These unbalanced motions are 

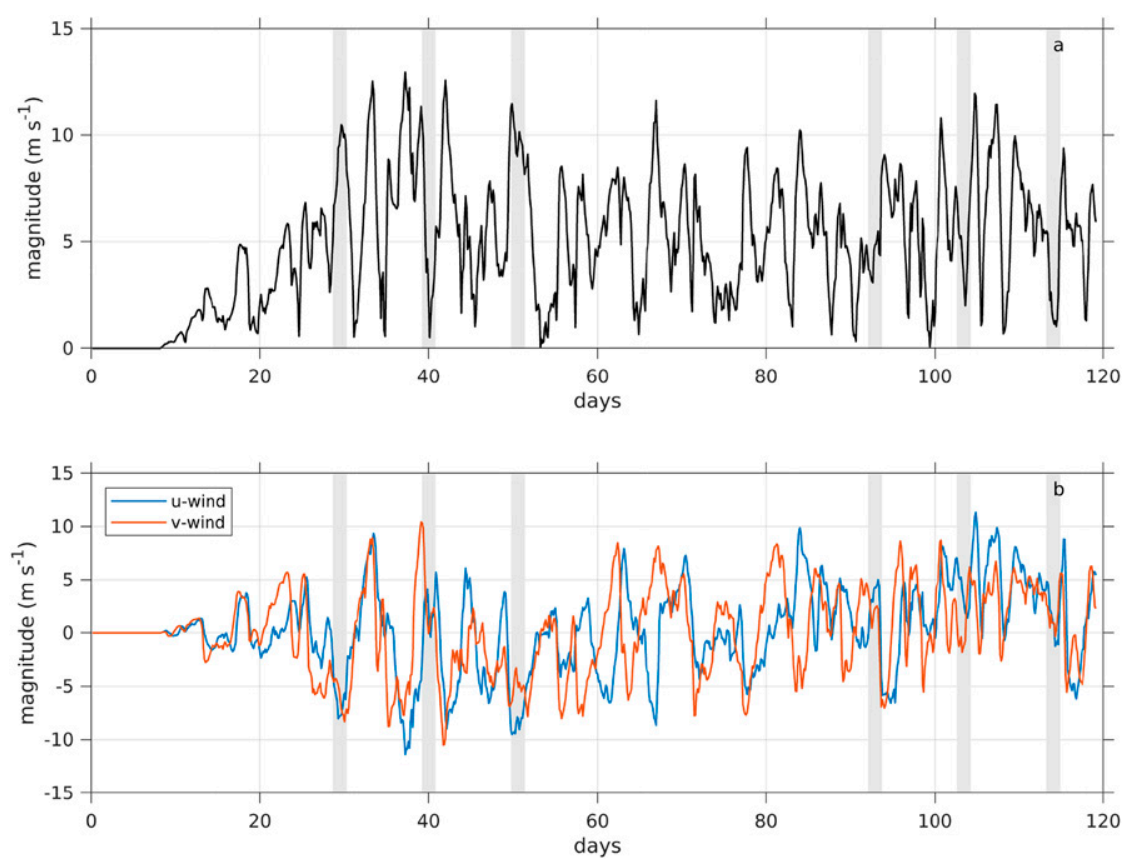

FIG. 7. (a) Wind magnitude and (b) eastward and northward components for experiment REAL. Vertical gray bars denote the time when the vertical velocity field was shown in Fig. 8.

excited by the changing wind forcing (e.g., Pollard 1970), and are otherwise virtually absent under idealized forcing scenarios. Also noticeable are instabilities (Fig. 8c), which mainly exist in the mixed layer, or upper $20-30 \mathrm{~m}$. These are presumably symmetric instabilities that arise when potential vorticity is of the opposite sign of the Coriolis (Hoskins 1974; Thomas et al. 2013; Brannigan 2016). These mixed layer instabilities are not the main focus of this study because of the much larger temporal and spatial scales of interest here. In the later stage of the ring, the vertical velocity starts to develop quadrupolar patterns (Figs. 8d-f). These patterns are distinctive from the patterns associated with Ekman pumping and wave motions. The alternating upwelling and downwelling cells are relatively persistent, with large magnitude up to $2.3 \mathrm{~m} \mathrm{day}^{-1}$ over two initial periods, larger than Ekman pumping velocity with $\sim 10 \mathrm{~m} \mathrm{~s}^{-1}$ wind (Fig. 8a).

The diagnosis of the vertical velocity further contrasts the different dynamical processes during the life span of the ring. Similar to periodic wind forcing scenarios [section 3b(1)], the vertical velocity calculated based on Eq. (5) (rhs w) matches the primitive model solution well, suggesting the vertical velocity field averaged over two inertial periods reflects the balanced motions. In other words, unbalanced wave motions are well controlled. In the early stage, again the vertical velocity field resembles the Ekman pumping pattern (Fig. 9a). As is the case with idealized forcing scenario, the combination of Ekman divergence and vorticity imbalance determines the vertical velocity. However, in the later stage, Ekman dynamics cannot explain the spatial pattern of the vertical velocity (Fig. 9e). Although the nonlinear advection of vorticity still does not balance the local vorticity change, the upwelling associated with $w_{c}$ is rather weak (Fig. 9h). This is because the ring is no longer circular (Fig. 8), which is likely resulted from the interactions between the ring with ambient wind-driven circulation and unbalanced wave motions. As such, the interaction between wind and the noncircular ring does not necessarily produce Ekman divergence. Instead, the quadrupolar velocity pattern is more likely induced by strain deformation. This can be verified by the generalized omega equation solutions.

The diabatic, generalized omega equation [section 2c(1)] captures the quadrupolar spatial pattern of the vertical velocity at the later stage of the ring, although the magnitude is slightly underestimated (Fig. 10). At this time, the ring is noncircular, with elongation in the eastwest direction. The alternating upwelling and downwelling cells around the periphery of the ring are primary resulted from the strain deformation (Fig. 10b), with comparable contribution from the geostrophic and ageostrophic components (Figs. 10c,d). The vertical mixing of momentum and buoyancy does not noticeably contribute to the vertical velocity field (Fig. 10f), presumably because we are examining the vertical velocity below the surface boundary layer. It is worth noting that the result here suggests that inference of vertical velocity using the 

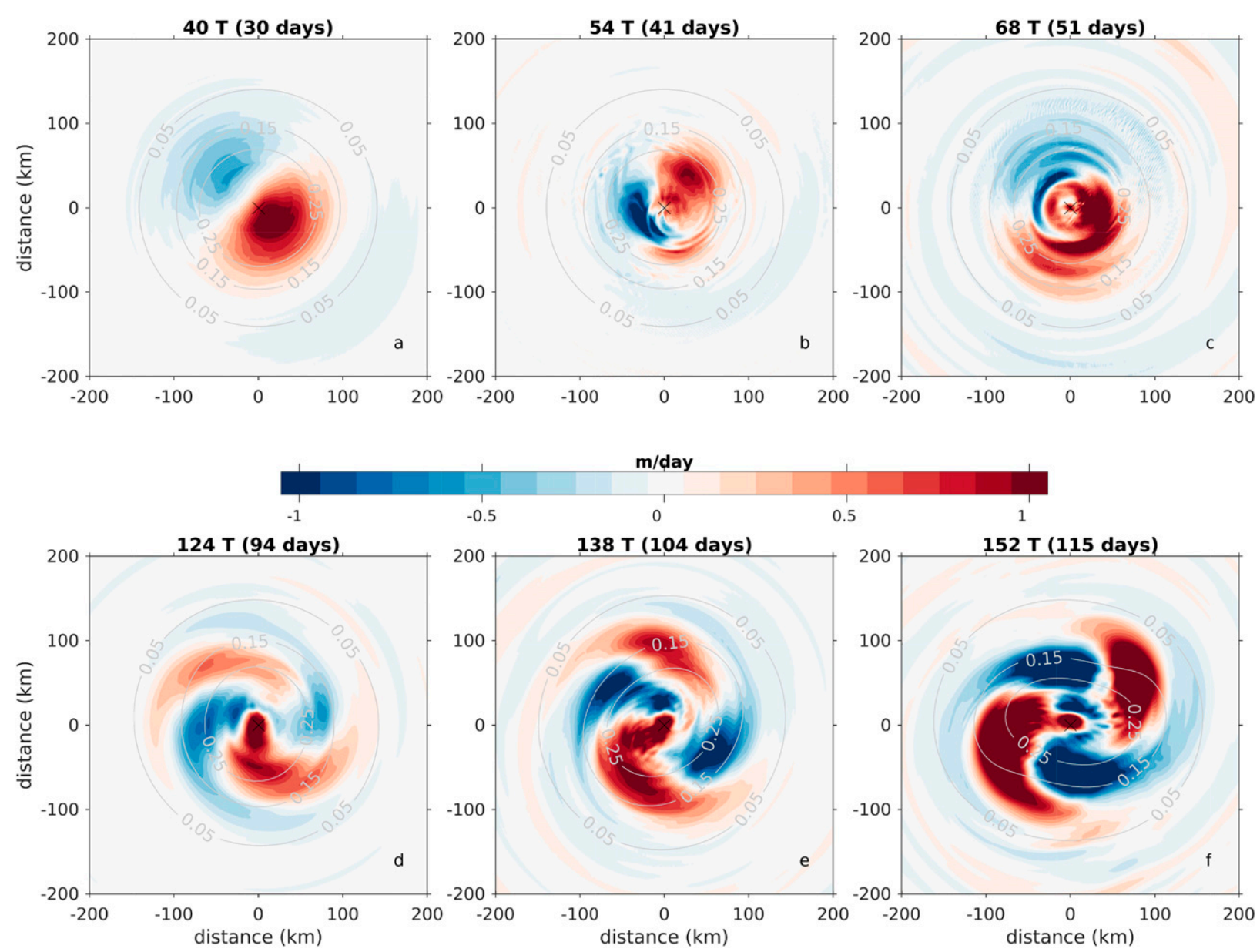

FIG. 8. Plan view of the mean vertical velocity field at $50 \mathrm{~m}$ from experiment REAL during initial periods (a) 39-40, (b) 53-54, (c) 67-68, (d) 123-124, (e) 137-138, and (f) 151-152. The sea surface height anomalies are contoured in gray.

quasigeostrophic omega equation would further underestimate the actual vertical velocity. This is in agreement with the result reported by Viúdez and Dritschel (2004) that for flows containing only negative potential vorticity, the QG vertical velocity is always smaller than the magnitude of the total vertical velocity, particularly for high Rossby numbers. The QG omega equation, however, is still a valid diagnostic tool for low Rossby number regimes and is very convenient because it only requires the knowledge of the density field (Holton 2004, his section 6.4). The omission of the ageostrophic deformation and advection will lead to an underestimate of the total $w$ in anticyclonic eddies.

We have further evaluated the neglected terms in the omega equation, including the nondiagnostic terms (i.e., terms containing $w) f\left[\left(\partial \zeta_{z}^{\prime} / \partial t\right)+\mathbf{u}_{h} \cdot \nabla_{h} \zeta_{z}^{\prime}\right], \nabla_{h} \varrho_{z} \cdot \nabla_{h} w$, $-f \zeta_{p h z}^{\prime} \cdot \nabla_{h} w$ and the diagnostic part of $f\left(d \zeta_{z}^{\prime} / d t\right)$, which is $f\left[\left(\partial \zeta_{z}^{\prime} / \partial t\right)+\mathbf{u}_{h} \cdot \nabla_{h} \zeta_{z}^{\prime}\right]$. It is found that the magnitudes of the nondiagnostic forcing terms are relatively small and can indeed be safely neglected. While the term $f\left[\left(\partial \zeta_{z}^{\prime} / \partial t\right)+\mathbf{u}_{h} \cdot \nabla_{h} \zeta_{z}^{\prime}\right]$ has relatively larger magnitude in general, it represents very noisy signals due to its nature of higher-order derivatives, and including $f\left[\left(\partial \zeta_{z}^{\prime} / \partial t\right)+\mathbf{u}_{h} \cdot \nabla_{h} \zeta_{z}^{\prime}\right]$ in the calculation of omega equation does not change the main result noticeably (not shown).

As the omega solutions suggest, the periphery of the ring experiences different deformation processes. Although the strain field $S=\sqrt{\left(u_{x}-v_{y}\right)^{2}+\left(v_{x}+u_{y}\right)^{2}}$ is acting on the entire periphery of the ring (Fig. 11b), the deformation depends on the direction of the principal strain axis relative to the density gradient (Gula et al. 2014). When the principal strain axis is in the same direction as the front or perpendicular to the density gradient, the front intensifies, that is, this part of the ring periphery experiences frontogenesis. On the other hand, if the principal strain axis is not in the same direction as the frontal direction, the strain field will act to weaken the front or density gradient, that is, frontolysis occurs. This can be revealed by the frontal tendency term, 

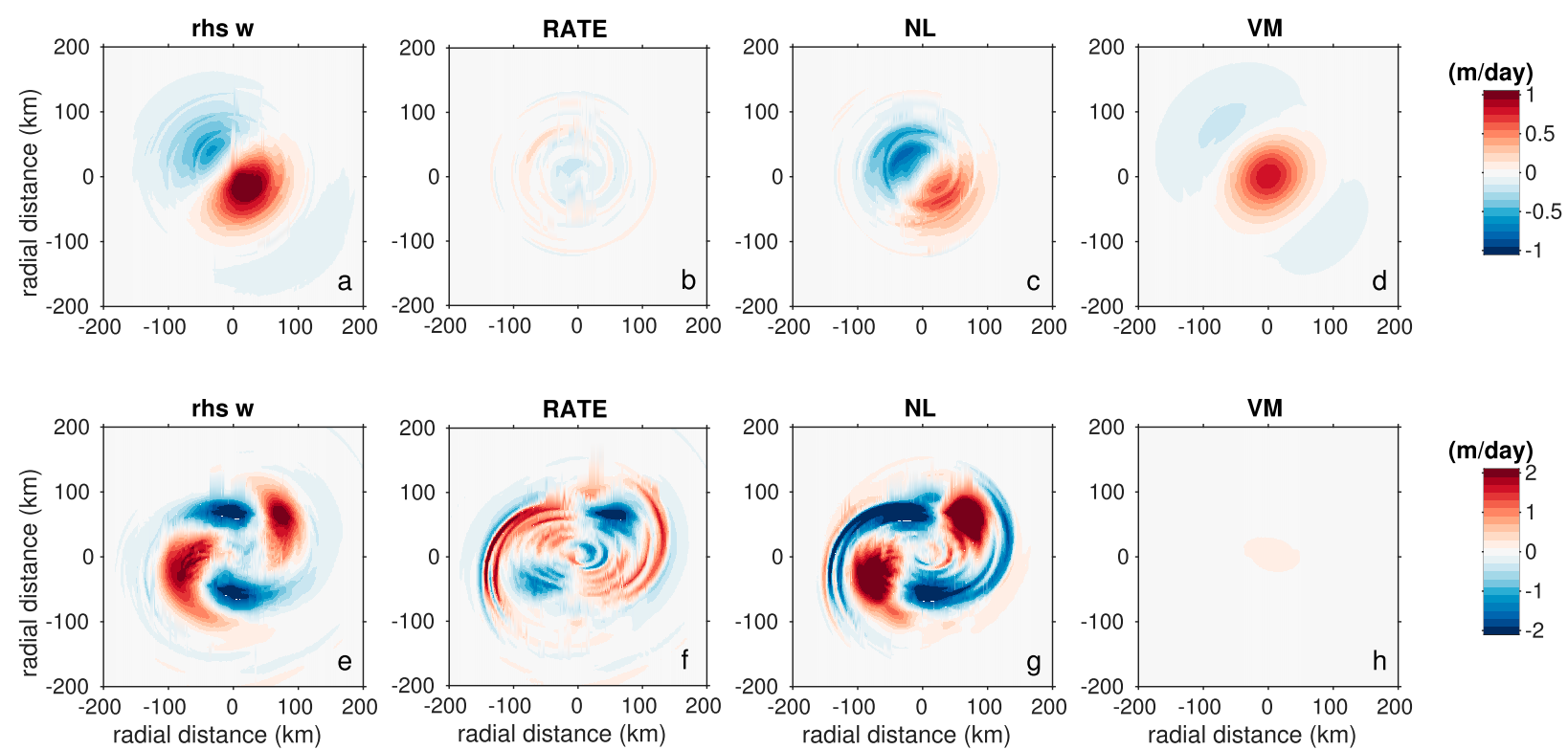

FIG. 9. Diagnostic terms of vertical velocity at $50 \mathrm{~m}$ for the (top) early stage (inertial periods 39-40) and (bottom) late stage (inertial periods 151-152) (a),(e) vertical velocity calculated from the semidiagnostic equation [Eq. (5)], and contributions from (b),(f) time rate of change of relative vorticity, (c), (g) advection of vorticity (including both horizontal and vertical), and (d),(h) vertical mixing of momentum. Only the leading terms in Eq. (5) are shown. Note the different color scale.

$$
T=\frac{1}{2} \frac{D\left\|\nabla_{h} \rho\right\|}{D t} \approx T_{\mathrm{adv}}=\mathbf{Q}_{\mathrm{adv}} \cdot \nabla_{h} \rho,
$$

where $\mathbf{Q}_{\mathrm{adv}}=-\nabla_{h} \mathbf{u}_{h} \cdot \nabla_{h} \rho=-\left(\rho_{x} u_{x}+\rho_{y} v_{x}, \rho_{x} u_{y}+\rho_{y} v_{y}\right)$ is essentially the $\mathbf{Q}_{h}$ vector in the omega equation [Eq. (4)]. Here only the contribution from the horizontal advection is formulated so $T_{\text {adv }}$ reflects the change of frontal sharpness and density gradient by the straining of the horizontal velocity field (Hoskins 1982). The tendency term reveals alternating frontogenesis and frontolysis around the periphery of the ring (Fig. 11c). Although other terms, for example, contributions from vertical advection and mixing are not included in the tendency calculation, the horizontal strain clearly contributes to the alternating upwelling/downwelling cells around the periphery of the ring (Fig. 10a), consistent with the diagnosis using the omega equation.

\section{The scale dependence of vertical nutrient delivery}

The convolution of frictional decay, vorticity gradientand current-induced Ekman pumping, strain deformation and unbalanced wave motions over the lifespan of a warm core ring makes it intriguing to investigate the contributions of each process to the vertical nutrient transport, which is one of the most fundamental processes sustaining the upper-ocean ecosystem. To do so, we consider the nutrient budget in the upper ocean, with the influence of
WCRs under various scenarios. The nutrient field is constructed using a nutrient-density relationship (Fig. 12), as is commonly done in earlier studies (e.g., McGillicuddy and Robinson 1997). The scarcity of nutrient data prevents the possibility of having a three-dimensional nutrient field and thus using a density-nutrient relationship is the only way by which the realistic nutrient field can be reconstructed. It is worth noting the importance of using a realistic nutrient field as the transport highly depends upon the vertical gradient. In other words, it is not always appropriate to prescribe a vertical distribution function to the nutrient field, or assume unlimited nutrient content below a certain depth. The nutrient (interchangeable with nitrate here) content $(N)$ in this study is estimated as follows:

$$
\begin{array}{ll}
N=1.6 \sigma_{T}-40.5, & 24.5 \leq \sigma_{T}<26.6 \\
N=31.8 \sigma_{T}-845.1, & 26.6 \leq \sigma_{T}<27.3 \\
N=-10.5 \sigma_{T}+311.0, & 27.3 \leq \sigma_{T}<28 .
\end{array}
$$

In addition, the minimum value is set to be $0.02 \mathrm{mmol} \mathrm{kg}^{-1}$, the lowest value recorded in the dataset (section $2 \mathrm{a}$ ). The unit is further converted to $\mathrm{mmol} \mathrm{m}^{-3}$, by multiplying the water density.

The nutrient transport under different forcing scenarios can be contrasted by focusing on the evolution of nutrient concentration in the upper $50 \mathrm{~m}$ over time (Fig. 13). As the purpose is to isolate and compare the effectiveness of different processes in transporting nutrient, we first treat 

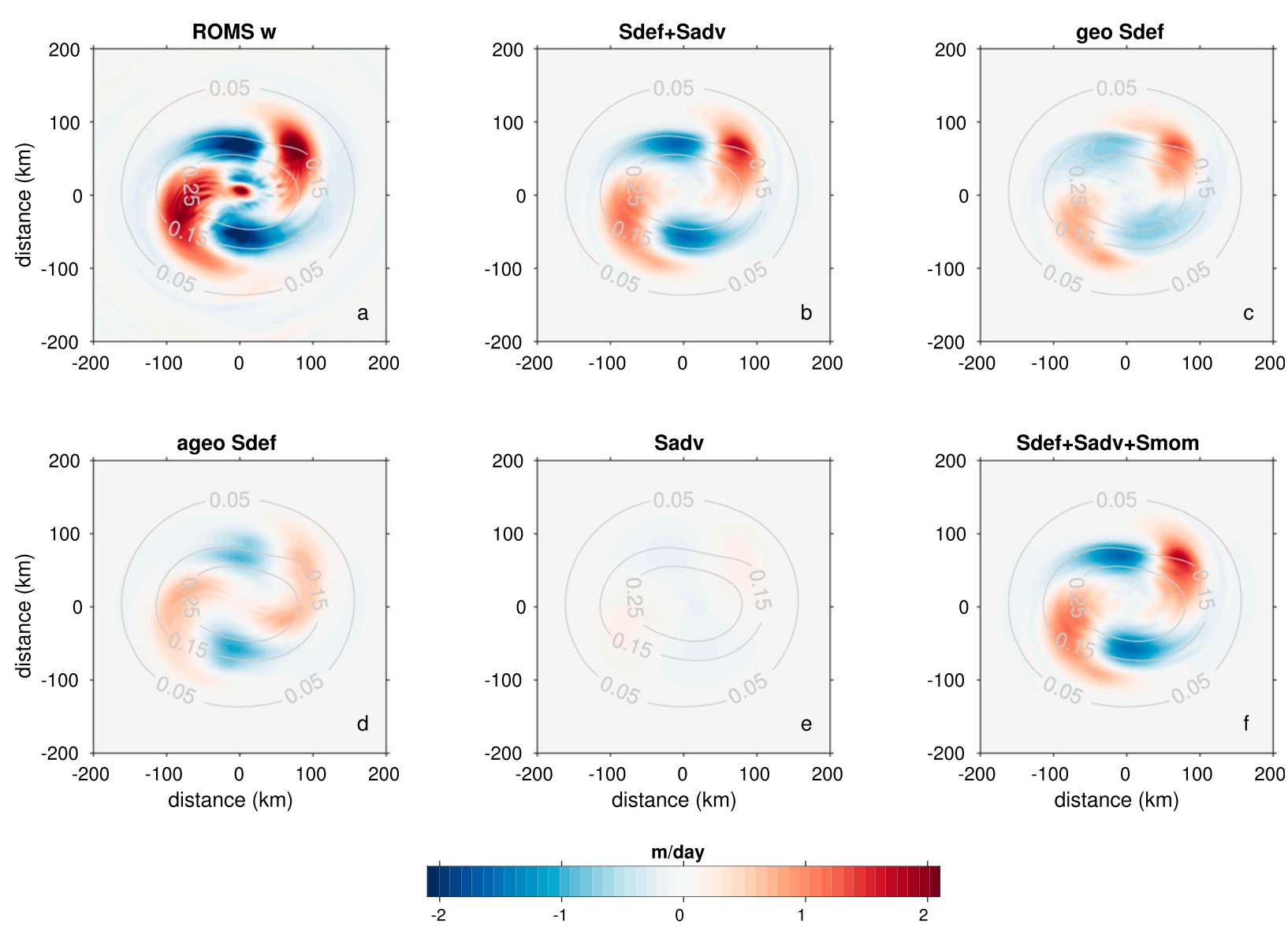

FIG. 10. Omega equation solutions for the later stage, inertial periods 151-152. (a) Vertical velocity from ROMS. Vertical velocity induced by (b) the strain deformation and ageostrophic advection, (c) geostrophic strain deformation, (d) ageostrophic strain deformation, (e) ageostrophic advection, and (f) strain deformation, ageostrophic advection, and vertical mixing of momentum. The sea surface height anomalies are contoured in gray.

nutrient as passive tracer to make comparisons across highly idealized scenarios possible. This approach focuses more on the physical processes, regardless of the fate of the nutrient within the ecosystem. In addition, we also conduct an experiment using a coupled nutrient-phytoplankton-zooplankton-detritus (NPZD) model embedded within our idealized WCR (see below).

Without external forcing, the change of average nutrient concentration in the upper $50 \mathrm{~m}$ is rather small (Fig. 13). This can be understood, as the vertical mixing is the only operating process, which acts to transport very limited nutrient upward. With wind forcing imposed, the response of the nutrient field is dramatically different. With only $w_{\zeta}$, the transport of nutrient to the upper $50 \mathrm{~m}$ is almost indistinguishable from the case without wind forcing. In comparison, with $w_{c}$ included, the nutrient concentration has a significant increase. This difference suggests that $w_{c}$ is more effective in delivering nutrient to the upper ocean at the scale of a warm core ring's life span from days to months. Under more realistic atmospheric forcing conditions, the transport of nutrient to the upper ocean is not much different from the case with only Ekman pumping, although strain deformation can induce vertical velocity of larger magnitude than those of Ekman pumping velocities. Note that the time-varying wind magnitude in the experiment REAL does not consistently exceed $7.5 \mathrm{~m} \mathrm{~s}^{-1}$ as in experiment RWIND, but we do see larger nutrient delivery between day 30 and 40, when the wind magnitude is larger than $7.5 \mathrm{~m} \mathrm{~s}^{-1}$ most of the time (Fig. 7a). While $w_{c}$ acts in the center of the ring, $w_{\zeta}$ and deformation-induced vertical velocities act in the outer part of the ring. However, even when integrated over a radius of $100 \mathrm{~km}$, it is the presence of $w_{c}$ that makes the difference in effective nutrient delivery.

To further understand the processes in nutrient dynamics, we diagnose the nutrient budget in the 

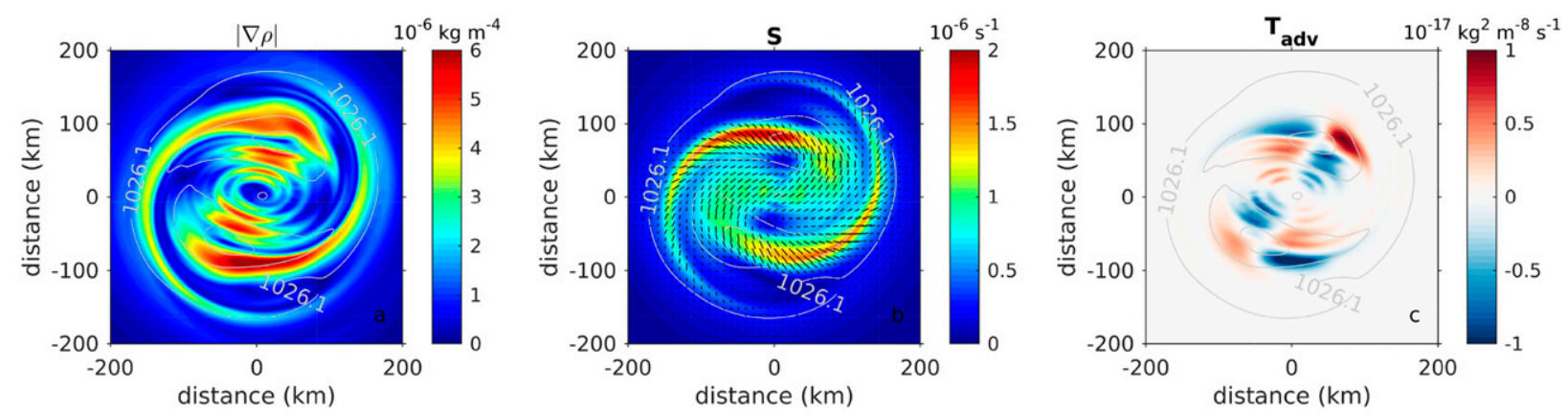

FIG. 11. Frontal diagnostic terms at $50 \mathrm{~m}$ for the later stage, inertial periods 151-152. (a) Front sharpness and (b) strain rate with the principal strain axis shown in black lines. (c) Frontal tendency by horizontal advection. The density field is contoured in gray.

experiment REAL using an NPZD model. In this case, the source and sink of nutrient including phytoplankton uptake, zooplankton excretion, and detritus remineralization are considered, based on the work of Powell et al. (2006) with the governing equations and parameters described in the appendix. The diagnostic terms in the nutrient budget over a life span of WCRs, which varies from less than a month to several months, highlights the interplay of several physical processes (Fig. 14). Overall, the nutrient concentration increased in the center of the ring over the term of $\sim 120$ days of simulation analyzed here. Notable exceptions occurred in the near-surface layer (to a depth of $40 \mathrm{~m}$ ) where the uptake of nutrient was significant. The structure of nutrient variability is determined by a combination of horizontal advection, vertical advection, vertical mixing, and biological activities. Specifically, the integration of Ekman pumping played an important role in vertical nutrient transport within the ring, by which the nutrient concentration increased $\sim 2 \mathrm{mmol} \mathrm{m}^{-3}$ around $50 \mathrm{~m}$ (not shown). This vertical flux of nutrient is partially cancelled by the horizontal advection, which represents the transport of nutrient from the core to the periphery. The different roles played by vertical and horizontal advection is consistent with the structure of the secondary circulation in Fig. 5. In combination, the total advection increases the nutrient concentration by $\sim 1 \mathrm{mmol} \mathrm{m}^{-3}$, with the maximum located between 30 and $40 \mathrm{~m}$. Vertical mixing acts to increase near-surface nutrient by mixing subsurface nutrient upward (Fig. 14c). In addition, vertical mixing increases the nutrient concentration at depth along a $\sim 20$-m band, tilting upward from the ring center to the periphery (Fig. 14c), consistent with the vertical nutrient gradient. This result emphasizes that the nutrient gradient can largely determine the effective nutrient flux and again highlights the importance of prescribing a realistic nutrient field for understanding its transport and ecosystem response.

To better understand various components in the vertical velocity field, particularly the relative contributions of Ekman pumping velocities to the overall vertical nutrient delivery during different stages of the WCR life span, we compute the nutrient flux terms $\langle W T\rangle$ induced by $w_{c}, w_{\zeta}$, and total vertical velocity at early (Fig. 15)
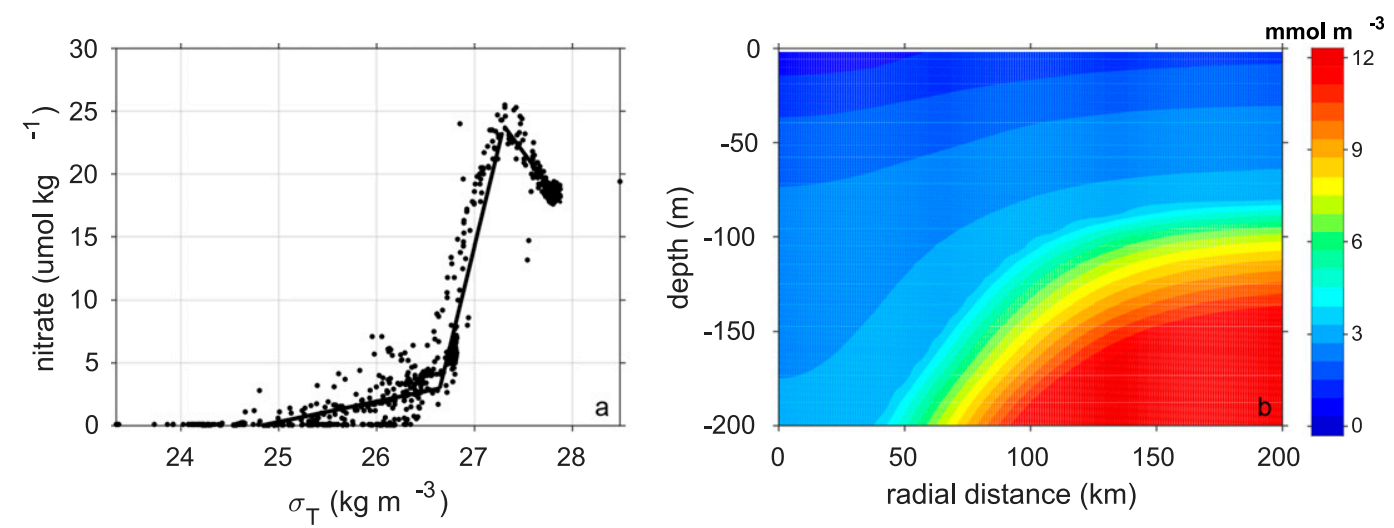

FIG. 12. (a) Nitrate-density relationship from the Warm Core Ring Program. The samplings cover four WCRs: $81 \mathrm{D}, 82 \mathrm{~B}, 82 \mathrm{E}$, and $82 \mathrm{H}$. In total, 75 quality-controlled profiles in the ring center and 828 data points represent the mean structure of the WCRs. (b) Initial nitrate distribution based on (a). Note the conversion of the nitrate unit. 

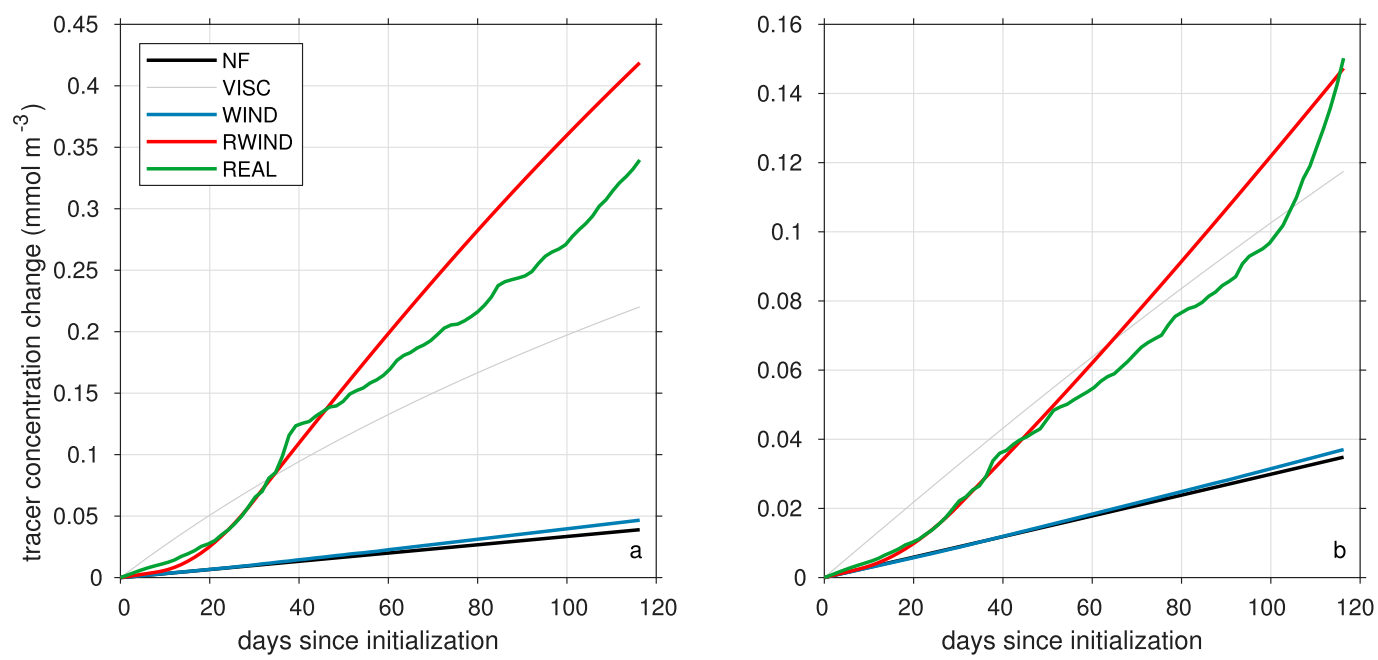

FIG. 13. Changes of nutrient concentration in the upper $50 \mathrm{~m}$ within a radius of (a) 50 and (b) $100 \mathrm{~km}$. For WIND, RWIND, and REAL, the first 30 days is the ramp-up period.

and late (Fig. 16) stages of the WCR. Note here $\langle W T\rangle=\langle\bar{W} \bar{T}\rangle+\left\langle W^{\prime} T^{\prime}\right\rangle$, so the total fluxes during two inertial periods are considered. At the early stage, the ring is circular with a maximum vorticity of $0.3 f$. The $w_{c}$ and $w_{\zeta}$ components of the Ekman pumping are consistent with the canonical patterns, with a monopolar and dipolar pattern, respectively. Because of the ubiquitous internal waves, $w_{\zeta}$, which contains higher-order derivatives of vorticity [Eq. (6)], exhibits a wave pattern in the radial direction. The spatial patterns of vertical fluxes of nutrients across $50 \mathrm{~m}$ resemble the patterns of vertical velocities, something we expect based on the reconstructed nutrient field (Fig. 12). The total nutrient flux can be largely explained by the combined contributions of $w_{c}$ and $w_{\zeta}$. At the later stage of the WCR, however, contrasting results exist. The ring has apparently become noncircular, with decreased vorticity of
$0.22 f$. The vertical nutrient fluxes by Ekman pumping velocities still resemble the corresponding vertical velocity field, which has undergone significant modifications from the early stage. Also in contrast to the early stage, the total nutrient flux cannot be explained by the combination of Ekman fluxes (Figs. 16d-f). Instead, this quadrupolar pattern is attributed to the vertical velocity field induced by strain deformation (Fig. 10).

The comparison of nutrient fluxes at the early and late stages of the WCR reveals the complex time dependence of the vertical processes embedded here. To further elucidate the temporal and spatial scales associated with different processes, we construct radius versus time plots, similar to a Hovmöller diagram, of nutrient fluxes along one radial section (Figs. 17a-c). The nutrient flux by $w_{c}$ has a relatively consistent pattern over time:
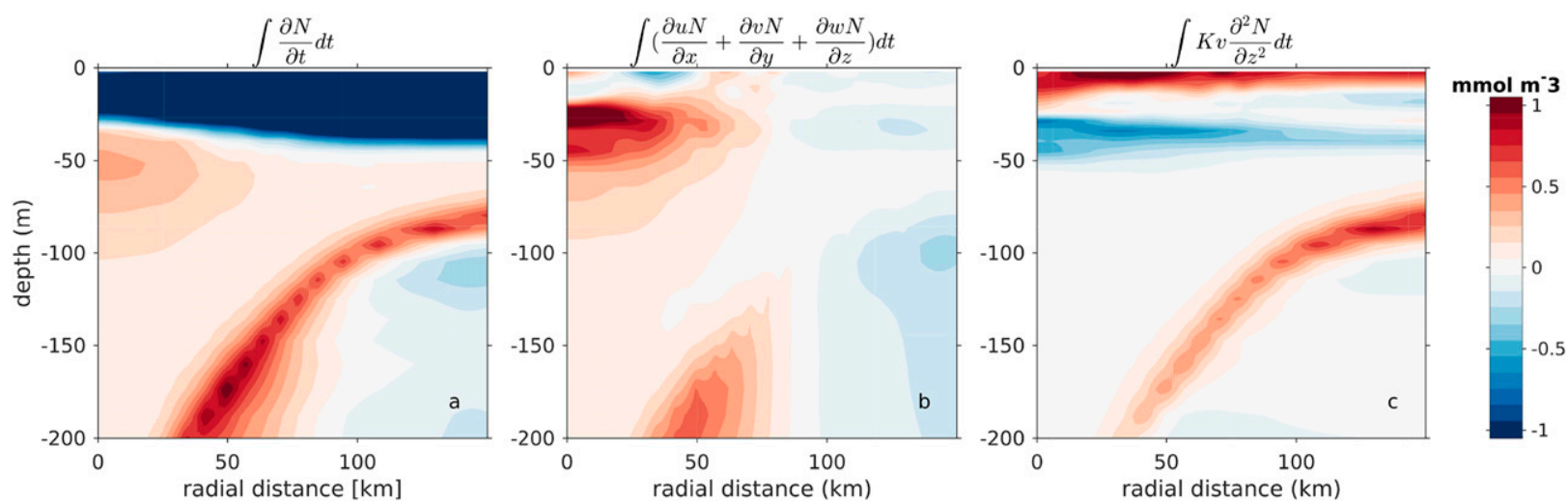

FIG. 14. Nutrient budget diagnostic terms for the first 90 days after initialization in experiment REAL. (a) Change of nutrient concentration. (b) Advection of nutrient. (c) Vertical mixing of nutrient. All terms are azimuthally averaged. 

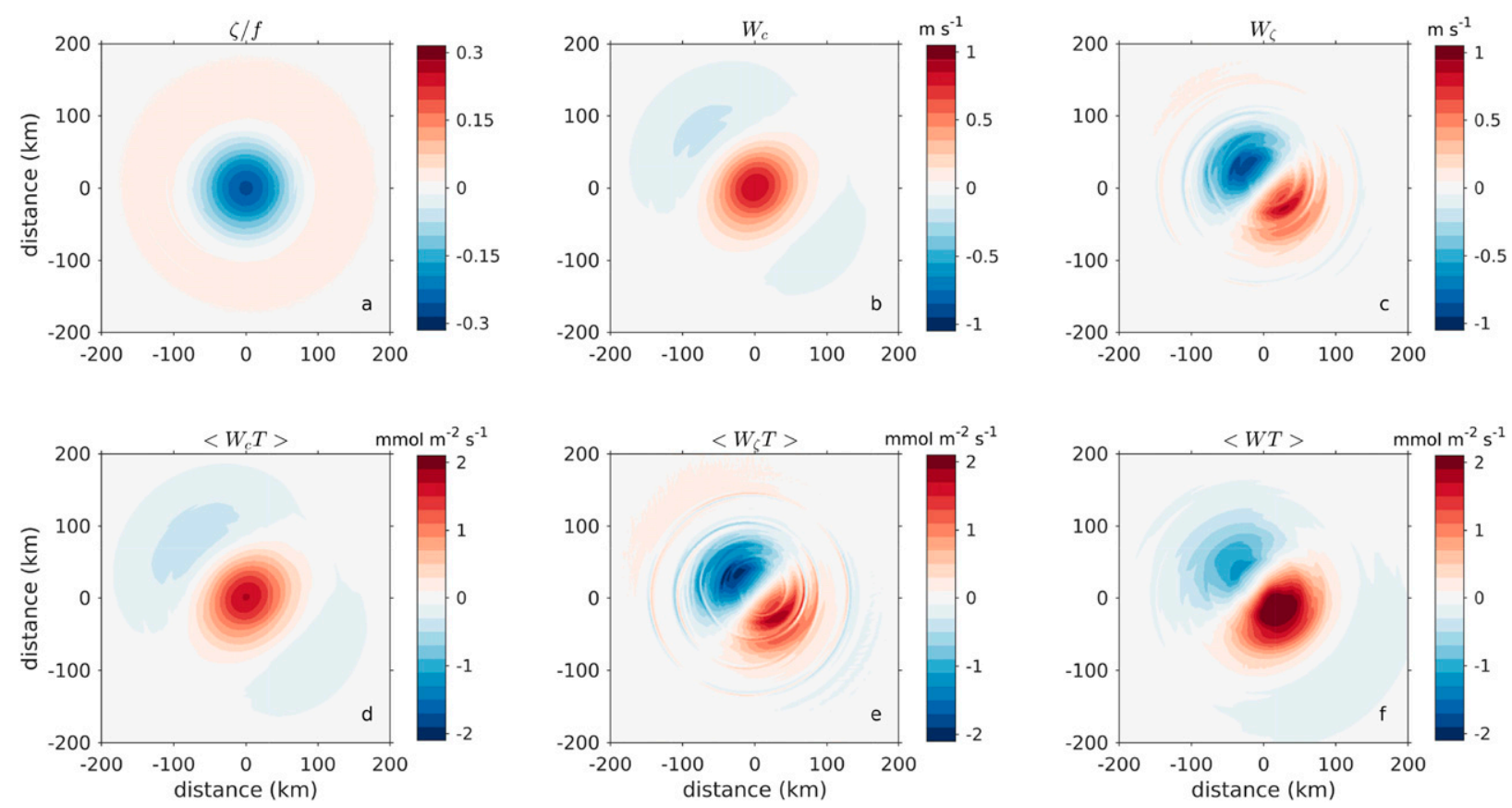

FIG. 15. Vorticity and vertical terms during inertial periods 39-40. (a) Surface vorticity (scaled by the Coriolis parameter), (b) currentinduced Ekman vertical velocity, (c) vorticity gradient-induced Ekman vertical velocity, and (d)-(f) nutrient fluxes by $w_{c}$, $w_{\zeta}$, and total vertical velocity at $50 \mathrm{~m}$.

positive (upward) close to the core of the ring and negative (downward) toward the periphery. The magnitude of the upwelling/downwelling is consistent with the wind speed (Fig. 17g), for example, noticeably larger flux around days 30-40 when wind is stronger. As expected, the size of the secondary circulation cell, that is, the border between the upwelling region and downwelling region, also varies with the wind. In comparison, the nutrient fluxes by $w_{\zeta}$ is less consistent. The alternating upwelling/downwelling pattern is a result of timevarying wind direction, which, however, does not persist over time. This is probably due to the ramification of near inertial waves and strain deformation, which modify the vorticity field. The upwelling and downwelling regions do seem to be located away from the eddy center though, consistent with the theoretical calculation. As expected from the analysis above, the combination of nutrient fluxes by $w_{c}$ and $w_{\zeta}$ do not constitute the total nutrient flux. The total nutrient flux is mostly upward, located near the center of the ring. It is worth noting that the diagram is based on $\langle W T\rangle$, average nutrient flux during two inertial periods, which is about 1.5 days and is a meaningful time scale for phytoplankton growth. So the positive fluxes in Fig. 17 represent persistent nutrient supply over this time scale, which should be able to be fully utilized.

Ultimately, we are interested in understanding the role of WCRs in the nutrient delivery at the spatial and temporal scales of the ring itself. Therefore, we further compute the integrals of nutrient fluxes $\iint\langle W T\rangle d t d A$, where $\int d t$ denotes the integration over time, and $\int d A$ denotes the integration over area. Overall, the net contribution of WCRs to nutrient transport is positive (Fig. 17f). Within the radius of $100 \mathrm{~km}$ and over the course of $\sim 120$ days, more than 400 million moles nitrate is injected to the upper $50 \mathrm{~m}$. The contributions in nutrient delivery by $w_{c}$ and $w_{\zeta}$ are drastically different. Because of the consistent upward velocity, the integrated nutrient injection by $w_{c}$ is consistently positive and the maximum is around the radius of the ring $(\sim 100 \mathrm{~km})$. This is because of the secondary circulation cell: the weak downwelling outside of the ring suppresses the upward nutrient injection (Fig. 5). Nevertheless, the nutrient injection by $w_{c}$ over $\sim 120$ days is more than 600 million moles. On the other hand, the nutrient injection by $w_{\zeta}$ at the scales of interest here is much smaller. This is a surprising, yet understandable result because the theoretical gradient-induced vertical velocities tend to cancel out when integrating over the scale of a ring. Note the total nutrient flux (Fig. 17f) includes the contribution from $w_{c}$ and $w_{\zeta}$, strain deformation, and unbalanced wave motions, yet the result really highlights the importance of $w_{c}$ in upward nutrient transport and sustaining the ecosystem in long-lived anticyclones. 

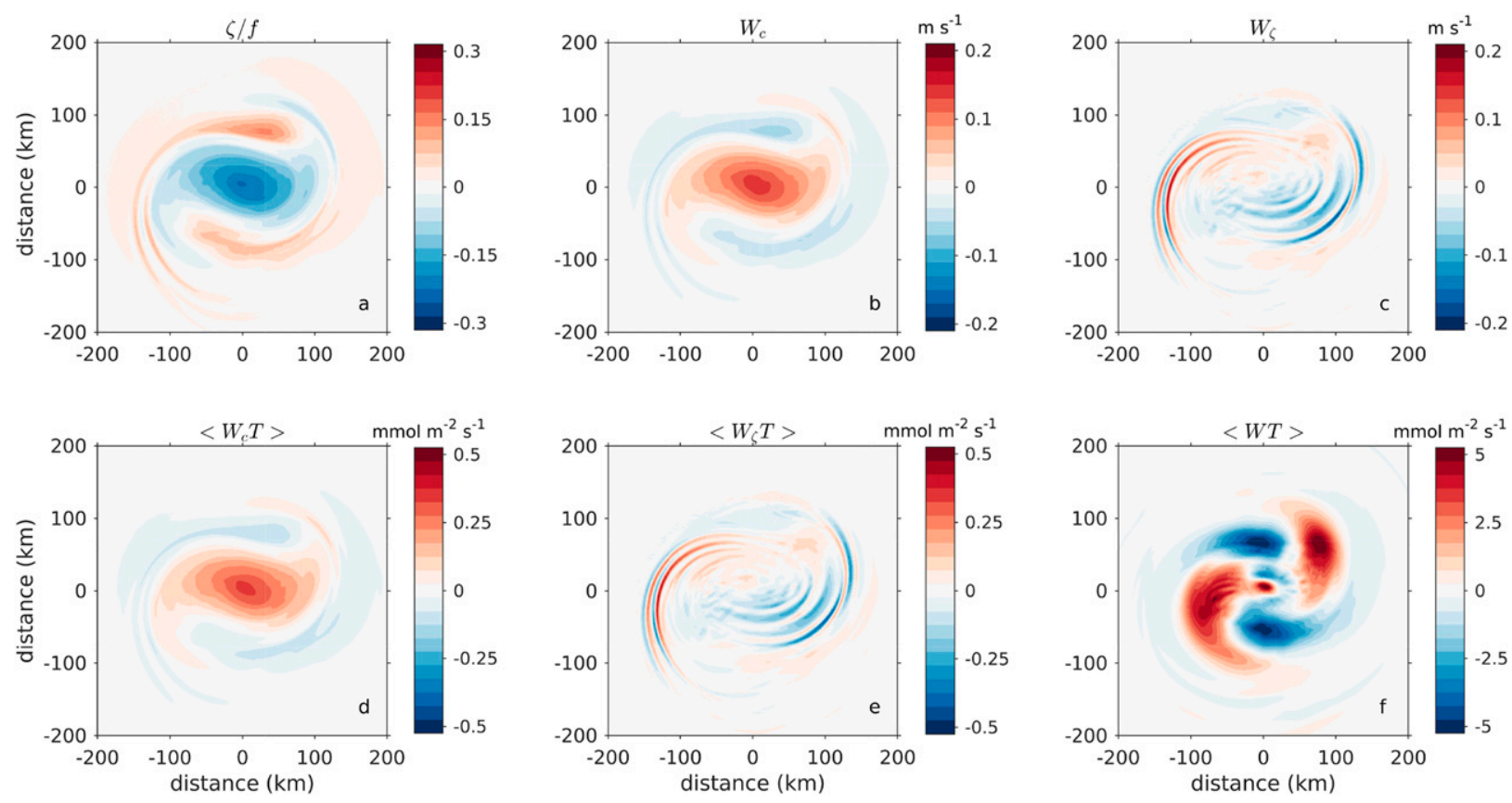

FIG. 16. Vorticity and vertical terms during inertial periods 151-152. (a) Surface vorticity (scaled by the Coriolis parameter), (b) currentinduced Ekman vertical velocity, (c) vorticity gradient-induced Ekman vertical velocity, and (d)-(f) nutrient fluxes by $w_{c}, w_{\zeta}$, and total vertical velocity at $50 \mathrm{~m}$.

\section{Discussion and summary}

Vertical velocity associated with ocean mesoscale eddies is fundamentally important for upper-ocean ecosystem dynamics and the global climate system. Because of the challenges in systematically observing vertical velocity with sufficient spatial coverage (e.g., D'Asaro et al. 2018), indirect inference based on observations and numerical modeling have been the primary approaches to understanding the vertical velocity field at the ocean's mesoscale to submesoscale. However, observation-based indirect inference can be limited by the synoptic nature of observations, and the assumptions during the inference. Interpretation of vertical velocity in numerical simulations is often complicated by different processes and is not always straightforward. These challenges further limit our understanding of the vertical transport of material in mesoscale eddies, which play important roles in ocean circulation, biology, and biogeochemistry (e.g., McGillicuddy 2016).

In this study, we attempt to advance the understanding of vertical velocity and nutrient delivery in large anticyclonic mesoscale eddies such as Gulf Stream warm core rings using idealized numerical modeling along with realistic reconstructions based on observations from the Warm Core Ring Program (Schink et al. 1982). We focus on evaluating the relative importance of mechanisms of vertical motions that are important for vertical nutrient delivery. As most of the historical observations are taken during warmer seasons, we use surface forcing conditions from April to July to match the hydrographic characteristics. Therefore, the results presented here are representative of Gulf Stream warm core rings in the spring and summer.

Dedicated numerical experiments are conducted to isolate and compare the vertical processes including frictional decay, current- (linear, $w_{c}$ ) and vorticity gradient-induced (nonlinear, $w_{\zeta}$ ) Ekman pumping, strain deformation, and vertical mixing. It is found that at the time scale of interest, which is over the life span of a ring, frictional decay contributes an almost negligible amount to vertical velocity and nutrient delivery in WCRs. This is in contrast to earlier work based on numerical modeling and observations (Flierl and Mied 1985; Olson et al. 1985; Franks et al. 1986), in which horizontal viscosity was considered the driving force for the decay of the warm core rings. Instead, the decay process is only comparable to these earlier works when a horizontal viscosity that is two orders of magnitude larger than a physically realistic value is prescribed. In such a case, horizontal friction slows down the rotation, and induces upwelling in the center of the ring. The contrasting role of horizontal viscosity in the decay of warm core rings raises the question of whether or not friction plays a role in the decay of warm core rings and 

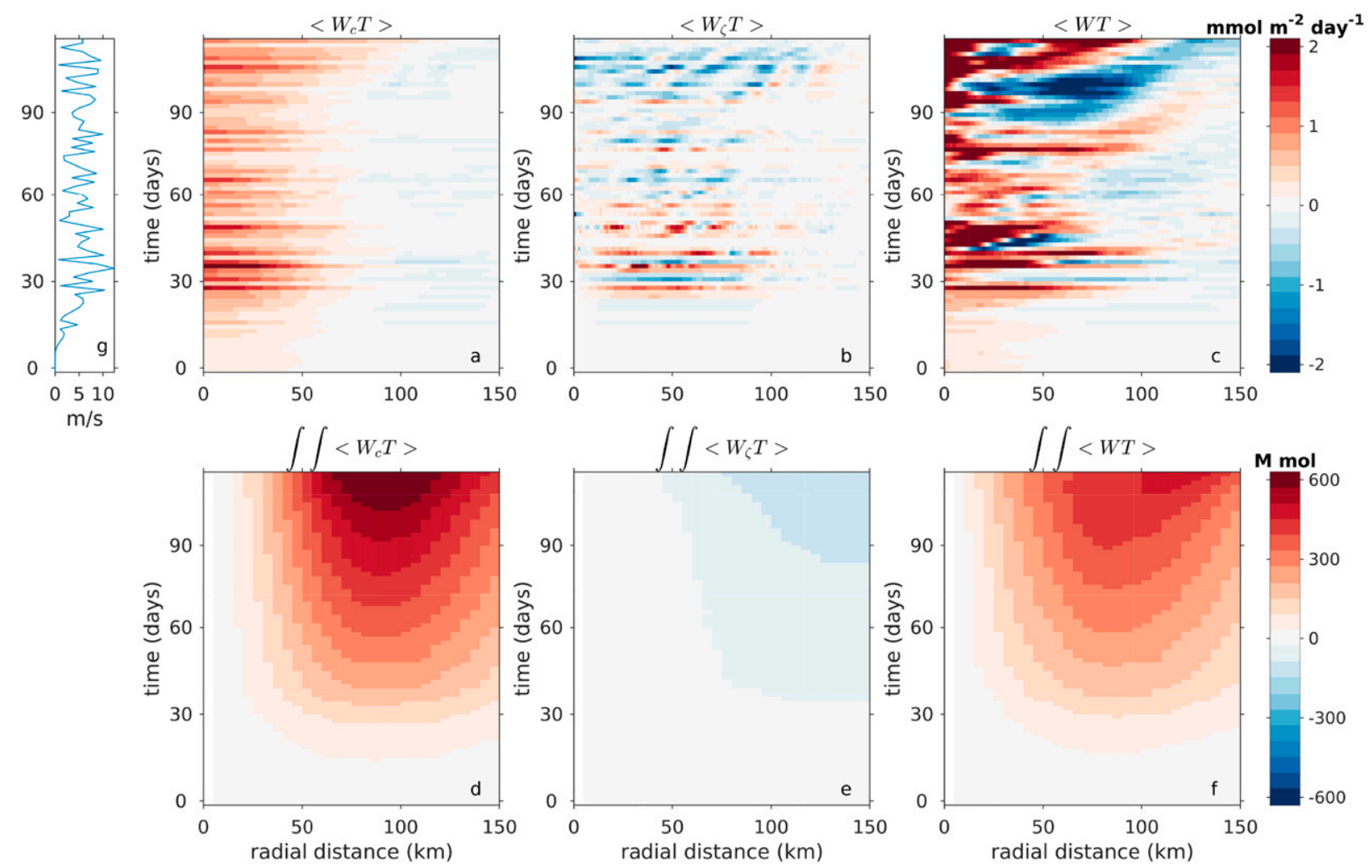

FIG. 17. Instantaneous vertical flux along one radial section at $50 \mathrm{~m}$ : (a) nutrient flux by $w_{c}$, (b) nutrient flux by $w_{\zeta}$, and (c) total vertical flux. Integrals of nutrient fluxes by (d) $w_{c}$, (e) $w_{\zeta}$, and (f) total vertical velocity with time and radial distance. The double integral represents the integration over area and time. Values represent the vertical injection of nutrient to the upper $50 \mathrm{~m}$. Wind speed appears in $(\mathrm{g})$.

associated upward nutrient delivery. It is plausible that the observed decay of warm core rings is reflecting the wind-forced decay, as the reported $\sim 1 \mathrm{~m} \mathrm{~s}^{-1}$ vertical velocity by Flierl and Mied (1985) and Olson et al. (1985) is comparable to current-induced Ekman pumping driven by a moderate wind speed of $7.5 \mathrm{~m} \mathrm{~s}^{-1}$. Other possible factors include the interaction with background flow and lateral topography, which are not considered in this study.

The current- and vorticity gradient-induced Ekman pumping velocities have distinct spatial and temporal characteristics. In typical oceanic conditions associated with warm core rings, the instantaneous $w_{\zeta}$ is larger than $w_{c}$. The exact ratio depends on the wind speed and the nonlinearity of the ring [see section $3 b(1)$ ]. However, at time scales from days to month, which are meaningful to marine ecosystems, $w_{\zeta}$ is not necessarily more important than $w_{c}$. Vorticity analysis further reveals contrasting balances in nonlinear, vorticity gradient-induced and linear, current-induced Ekman dynamics. In both scenarios, wind-driven advection increases the vorticity on the downwind flank of the ring and decreases the vorticity on the upwind flank. The imbalance between the vorticity advection and its local rate of change is reflected in vortex stretching and thus vertical velocity. With the consideration of the relative wind speed to the ocean current, Ekman divergence slows down the rotation, and induces persistent upwelling in the ring center.

Under more realistic forcing conditions, more intense vertical velocities can arise as the ring becomes noncircular. Both geostrophic and ageostrophic deformation contributes to the alternating upwelling/downwelling cells around the periphery of the ring. This is a result of the strain field acting on the density gradient. During this process, frontogenesis and frontolysis occur depending on the local directions of the density gradient and principal strain axes. Although the deformation of the ring appears toward the later stage of the isolated ring, this process could occur at any time in the real ocean when ambient flow field is present. In addition, submesoscale vertical motions, such as those associated with mixed layer instabilities (Brannigan 2016; Brannigan et al. 2017) appear with highly variable wind forcing, but generally do not dominate at the scales of interest considered here. In length discussions of the growth and decay of the submesoscale mixed layer instabilities and how they interact with the mesoscale 
TABLE A1. Parameters used in the NPZD model.

\begin{tabular}{|c|c|c|c|c|}
\hline Parameter name & Symbol & Value & Unit & Published values \\
\hline Light attenuation coefficient & $k_{z}$ & 0.067 & $\mathrm{~m}^{-1}$ & $0.04^{\mathrm{a}, \mathrm{b}}, 0.067^{\mathrm{c}}$ \\
\hline Self-shading coefficient & $k_{p}$ & 0.0095 & $\mathrm{~m}^{2} \mathrm{mmol} \mathrm{N}^{-1}$ & $0.0095^{\mathrm{c}}, 0.05^{\mathrm{d}}$ \\
\hline Initial slope of $P-I$ curve & $\alpha$ & 0.025 & $\mathrm{~m}^{2}(\mathrm{~W} \text { day })^{-1}$ & $0.009^{\mathrm{d}}, 0.025^{\mathrm{e}, \mathrm{c}}, 0.07^{\mathrm{f}}$ \\
\hline $\begin{array}{l}\text { Photosynthetically active fraction of } \\
\text { radiation }\end{array}$ & $\phi$ & 0.43 & - & $0.41^{\mathrm{e}}, 0.43^{\mathrm{b}}, 0.45^{\mathrm{a}}$ \\
\hline Nutrient uptake rate & $V_{m}$ & 1.5 & day $^{-1}$ & $1.5^{\mathrm{c}, \mathrm{d}}, 0.69-2.49^{\mathrm{e}}$ \\
\hline Uptake half saturation & $k_{N}$ & 1.0 & $\mathrm{mmol} \mathrm{N} \mathrm{m}^{-3}$ & $0.1^{\mathrm{f}}, 0.5^{\mathrm{e}, \mathrm{b}}, 1.0^{\mathrm{c}, \mathrm{d}}, 3.0^{\mathrm{g}}$ \\
\hline Phytoplankton senescence & $\sigma_{d}$ & 0.1 & day $^{-1}$ & $0.05^{\mathrm{d}}, 0.1^{\mathrm{c}}, 0.15^{\mathrm{b}}$ \\
\hline Zooplankton grazing rate & $R_{m}$ & 0.52 & day $^{-1}$ & $0.33^{\mathrm{d}}, 0.52^{\mathrm{c}}, 0.6^{\mathrm{b}}, 1.0^{\mathrm{h}}$ \\
\hline Ivlev constant & $\Lambda$ & 0.06 & $\mathrm{~m}^{3} \mathrm{mmol} \mathrm{N}^{-1}$ & $0.06^{\mathrm{c}}, 1.4^{\mathrm{g}}, 1.5^{\mathrm{d}}$ \\
\hline Excretion efficiency & $\gamma_{n}$ & 0.3 & - & $0.2^{\mathrm{d}}, 0.25^{\mathrm{e}, \mathrm{b}}, 0.3^{\mathrm{a}, \mathrm{c}, \mathrm{g}}$ \\
\hline Zooplankton mortality & $\zeta_{d}$ & 0.145 & day $^{-1}$ & $0.05^{\mathrm{e}}, 0.145^{\mathrm{c}}$ \\
\hline Remineralization & $\delta$ & 0.01 & day $^{-1}$ & $0.01^{\mathrm{b}}, 0.05^{\mathrm{e}}, 0.2^{\mathrm{a}}, 1.03^{\mathrm{c}}$ \\
\hline Detritus sinking velocity & $w_{d}$ & 8.0 & $m$ day $^{-1}$ & $0.1-1^{\mathrm{b}}, 1-10^{\mathrm{e}}, 5^{\mathrm{h}}, 8^{\mathrm{c}, \mathrm{d}}, 25^{\mathrm{a}}$ \\
\hline
\end{tabular}

${ }^{a}$ Lima and Doney (2004)

${ }^{\mathrm{b}}$ Fennel et al. (2006)

${ }^{\mathrm{c}}$ Powell et al. (2006)

d Zhang et al. (2013)

${ }^{\text {e }}$ Fasham et al. (1990)

${ }^{\mathrm{f}}$ Siedlecki et al. (2015)

${ }^{\mathrm{g}}$ Kishi et al. (2007)

${ }^{\mathrm{h}}$ Fasham (1995)

vertical velocity and material transport are beyond the scope of the current study, and will require dedicated numerical investigations taking into consideration at least the dependence of grid resolution, subgrid-scale viscosity, mixing scheme, and surface forcing field.

We further quantify the relative importance of frictional decay, $w_{c}$ and $w_{\zeta}$, strain deformation, vertical mixing, and unbalanced motions in vertical nutrient enrichment in warm core rings. To best represent the realistic nutrient field, we construct an initial nutrient field using a density-nitrate relationship derived based on the in situ observations from the Warm Core Ring Program. The diagnostic calculation of nutrient budget reveals that the vertical and horizontal nutrient advection, as a result of the secondary circulation in the vertical plane, work together to significantly elevate nutrient concentrations in the subsurface. Although mixing is more intensified near surface, the nutrient enrichment by vertical mixing is also concentrated at depth where the nutrient gradient is larger. This emphasizes the importance of using a realistic nutrient field in any estimate of nutrient injection to the upper ocean.

Our analysis highlights the temporal-scale dependence of nutrient by different processes. At a short time scale, for example, days, Ekman pumping velocities and deformationinduced velocity all contribute to the upward nutrient flux to the euphotic zone, and the latter dominates when a ring becomes noncircular. However, over a longer time scale, for example, the lifespan of a typical warm core ring, currentinduced Ekman pumping is the most effective mechanism in transporting nutrient upward. This is because of the persistent nature of the upwelling in the center of warm core rings, different from the dipolar pattern of vorticity gradient-induced pumping and alternating quadrupolar pattern in deformation induced velocities. Although vertical motions associated with submesoscale mixed layer instabilities can be very large, the effectiveness in vertical nutrient transport highly depends on the nutrient gradient, which is generally much smaller near surface than at depth. In that regard, persistent mesoscale motions acting on larger nutrient gradient at depth function as a primer in elevating nutrients in anticyclones for near surface submesoscale processes to act upon.

The results in this study are based on a representative warm core ring constructed from observations and reveals the complex nature of vertical velocity and nutrient delivery in these rings. While various vertical processes have been elucidated during the evolution of the ring, future work is warranted to place the above findings in a more realistic setting, where the presence of background flow and topographic features can be considered.

Acknowledgments. This work was supported by the National Science Foundation Ocean Science Division under Grant OCE-1558960. PG also acknowledges support of the NASA Physical Oceanography Program Grant NNX16H59G. KC would like to thank D. McGillicuddy Jr. for inspiring discussions and suggestions during the course of this study. Constructive comments from two anonymous reviewers are appreciated. 


\section{APPENDIX}

\section{NPZD Model}

The nutrient dynamics are modeled based on a lower-trophic level ecosystem model similar to the one in Powell et al. (2006), which considers the interactions of dissolved inorganic nutrient $N$, phototrophic phytoplankton $P$, herbivorous zooplankton $Z$, and sinking particulate detritus $D$. Here, we describe the governing equations of the system, along with the parameters used in this study to aid the discussions. For more details, the readers are referred to Powell et al. (2006).

$$
\begin{aligned}
& \frac{\partial N}{\partial t}+\mathbf{u} \cdot \nabla N=\delta D+\gamma_{n} \mathrm{GZ}-\mathrm{UP}+\frac{\partial}{\partial z}\left(k_{v} \frac{\partial N}{\partial z}\right), \\
& \frac{\partial P}{\partial t}+\mathbf{u} \cdot \nabla P=\mathrm{UP}-\mathrm{GZ}-\sigma_{d} P+\frac{\partial}{\partial z}\left(k_{v} \frac{\partial P}{\partial z}\right), \\
& \frac{\partial Z}{\partial t}+\mathbf{u} \cdot \nabla Z=\left(1-\gamma_{n}\right) \mathrm{GZ}-\zeta_{d} Z+\frac{\partial}{\partial z}\left(k_{v} \frac{\partial Z}{\partial z}\right), \\
& \frac{\partial D}{\partial t}+\mathbf{u} \cdot \nabla D=\sigma_{d} P+\zeta_{d} Z-\delta D+w_{d} \frac{\partial D}{\partial z}+\frac{\partial}{\partial z}\left(k_{v} \frac{\partial D}{\partial z}\right) .
\end{aligned}
$$

Here, $\delta D, \gamma_{n} \mathrm{GZ}$, and UP represent the remineralization of detritus, zooplankton excretion, and phytoplankton uptake; $\sigma_{d} P$ and $\zeta_{d} Z$ represent the mortality of phytoplankton and zooplankton; and $w_{d}$ represents the sinking velocity of detritus. Phytoplankton uptake is formulated as

$$
U=\frac{V_{m} N}{k_{N}+N} \frac{\alpha I}{\sqrt{V_{m}^{2}+\alpha^{2} I^{2}}},
$$

where $V_{m}$ is nutrient uptake rate, $k_{N}$ is half-saturation coefficient, $\alpha$ is the initial slope of $P-I$ (photosynthesisirradiance) curve, and $I$ is the irradiance profile:

$$
I(z)=\phi I_{0} \exp \left[k_{z} z+k_{p} \int_{z}^{0} P\left(z^{\prime}\right) d z^{\prime}\right],
$$

where $\phi$ is the photosynthetically active fraction of the shortwave radiation $I_{0}, k_{z}$ is the light attenuation coefficient, and $k_{p}$ is the phytoplankton self-shading coefficient.

Zooplankton grazing is formulated as

$$
G=R_{m}\left(1-e^{-\Lambda P}\right)
$$

where $R_{m}$ is the zooplankton grazing rate and $\Lambda$ is the Ivlev constant.

The parameters used in this study along with published values are listed in Table A1.

\section{REFERENCES}

Barceló-Llull, B., E. Pallàs-Sanz, P. Sangrà, A. Martínez-Marrero, S. N. Estrada-Allis, and J. Arístegui, 2017: Ageostrophic secondary circulation in a subtropical intrathermocline eddy. J. Phys. Oceanogr., 47, 1107-1123, https://doi.org/10.1175/ JPO-D-16-0235.1.

Berrisford, P., and Coauthors, 2011: The ERA-Interim Archive: Version 2.0. ERA Rep. Series 1, 23 pp., https://www.ecmwf.int/ sites/default/files/elibrary/2011/8174-era-interim-archive-version-20.pdf.

Brannigan, L., 2016: Intense submesoscale upwelling in anticyclonic eddies. Geophys. Res. Lett., 43, 3360-3369, https:// doi.org/10.1002/2016GL067926.

, D. P. Marshall, A. C. N. Garabato, A. J. G. Nurser, and J. Kaiser, 2017: Submesoscale instabilities in mesoscale eddies. J. Phys. Oceanogr., 47, 3061-3085, https://doi.org/10.1175/ JPO-D-16-0178.1.

Capet, X., J. C. McWilliams, M. J. Molemaker, and A. F. Shchepetkin, 2008: Mesoscale to submesoscale transition in the California current system. Part I: Flow structure, eddy flux, and observational tests. J. Phys. Oceanogr., 38, 29-43, https:// doi.org/10.1175/2007JPO3671.1.

Chapman, D. C., 1985: Numerical treatment of cross-shelf open boundaries in a barotropic coastal ocean model. J. Phys. Oceanogr., 15, 1060-1075, https://doi.org/10.1175/15200485(1985)015<1060:NTOCSO > 2.0.CO;2.

Chelton, D. B., and Coauthors, 2001: Observations of coupling between surface wind stress and sea surface temperature in the eastern tropical Pacific. J. Climate, 14, 1479-1498, https://doi.org/ 10.1175/1520-0442(2001)014<1479:OOCBSW >2.0.CO;2.

, M. G. Schlax, M. H. Freilich, and R. F. Milliff, 2004: Satellite measurements reveal persistent small-scale features in ocean winds. Science, 303, 978-983, https://doi.org/10.1126/ science.1091901.

, - - and R. M. Samelson, 2011a: Global observations of nonlinear mesoscale eddies. Prog. Oceanogr., 91, 167-216, https://doi.org/10.1016/j.pocean.2011.01.002.

— , P. Gaube, M. G. Schlax, J. J. Early, and R. M. Samelson, 2011b: The influence of nonlinear mesoscale eddies on nearsurface oceanic chlorophyll. Science, 334, 328-332, https:// doi.org/10.1126/science.1208897.

Chen, K., R. He, B. S. Powell, G. G. Gawarkiewicz, A. M. Moore, and H. G. Arango, 2014: Data assimilative modeling investigation of Gulf Stream Warm Core Ring interaction with continental shelf and slope circulation. J. Geophys. Res. Oceans, 119, 5968-5991, https://doi.org/10.1002/2014JC009898.

D'Asaro, E. A., and Coauthors, 2018: Ocean convergence and the dispersion of flotsam. Proc. Natl. Acad. Sci. USA, 115, 11621167, https://doi.org/10.1073/pnas.1718453115.

Dewar, W. K., 1986: Mixed layers in Gulf Stream rings. Dyn. Atmos. Oceans, 10, 1-29, https://doi.org/10.1016/0377-0265(86)90007-2. , and G. R. Flierl, 1987: Some effects of the wind on rings. J. Phys. Oceanogr., 17, 1653-1667, https://doi.org/10.1175/ 1520-0485(1987)017<1653:SEOTWO > 2.0.CO;2.

Dufois, F., N. J. Hardman-Mountford, J. Greenwood, A. J. Richardson, M. Feng, and R. J. Matear, 2016: Anticyclonic eddies are more productive than cyclonic eddies in subtropical gyres because of winter mixing. Sci. Adv., 2, e1600282, https://doi.org/10.1126/sciadv.1600282.

Early, J. J., R. M. Samelson, and D. B. Chelton, 2011: The evolution and propagation of quasigeostrophic ocean eddies. J. Phys. Oceanogr., 41, 1535-1555, https://doi.org/10.1175/2011JPO4601.1. 
Fairall, C. W., E. F. Bradley, J. E. Hare, A. A. Grachev, and J. B. Edson, 2003: Bulk parameterization of air-sea fluxes: Updates and verification for the COARE algorithm. J. Climate, 16, 571-591, https://doi.org/10.1175/1520-0442(2003)016<0571: BPOASF $>2.0 . \mathrm{CO} ; 2$.

Fasham, M. J. R., 1995: Variations in the seasonal cycle of biological production in subarctic oceans: A model sensitivity analysis. Deep-Sea Res. I, 42, 1111-1149, https://doi.org/ 10.1016/0967-0637(95)00054-A.

- H. W. Ducklow, and S. M. McKelvie, 1990: A nitrogenbased model of plankton dynamics in the oceanic mixed layer. J. Mar. Res., 48, 591-639, https://doi.org/10.1357/ 002224090784984678.

Fennel, K., J. Wilkin, J. Levin, J. Moisan, J. O'Reilly, and D. Haidvogel, 2006: Nitrogen cycling in the Middle Atlantic bight: Results from a three-dimensional model and implications for the North Atlantic nitrogen budget. Global Biogeochem. Cycles, 20, GB3007, https://doi.org/10.1029/2005GB002456.

Flierl, G. R., 1979: A simple model for the structure of warm and cold core rings. J. Geophys. Res., 84, 781-785, https://doi.org/ 10.1029/JC084iC02p00781.

— and spin down of a warm-core ring. J. Geophys. Res., 90, 8917-8927, https://doi.org/10.1029/JC090iC05p08917.

Franks, P. J. S., J. S. Wroblewski, and G. R. Flierl, 1986: Prediction of phytoplankton growth in response to the frictional decay of a warm-core ring. J. Geophys. Res., 91, 7603-7610, https:// doi.org/10.1029/JC091iC06p07603.

Friedrichs, M. A. M., and Coauthors, 2019: Ocean circulation causes strong variability in the Mid-Atlantic bight nitrogen budget. J. Geophys. Res. Oceans, 124,113-134, https://doi.org/ 10.1029/2018JC014424.

Garfield, N., and D. L. Evans, 1987: Shelf water entrainment by Gulf Stream warm-core rings. J. Geophys. Res., 92, $13003-$ 13 012, https://doi.org/10.1029/JC092IC12P13003.

Gaube, P., D. B. Chelton, P. G. Strutton, and M. J. Behrenfeld, 2013: Satellite observations of chlorophyll, phytoplankton biomass, and Ekman pumping in nonlinear mesoscale eddies. J. Geophys. Res. Oceans, 118, 6349-6370, https://doi.org/ 10.1002/2013JC009027.

— D. J. McGillicuddy, D. B. Chelton, M. J. Behrenfeld, and P. G. Strutton, 2014: Regional variations in the influence of mesoscale eddies on near-surface chlorophyll. J. Geophys. Res. Oceans, 119, 8195-8220, https://doi.org/10.1002/2014JC010111.

—, D. B. Chelton, R. M. Samelson, M. G. Schlax, and L. W. O'Neill, 2015: Satellite observations of mesoscale eddyinduced Ekman pumping. J. Phys. Oceanogr., 45, 104-132, https://doi.org/10.1175/JPO-D-14-0032.1.

Gawarkiewicz, G. G., F. Bahr, R. C. Beardsley, and K. H. Brink, 2001: Interaction of a slope eddy with the shelfbreak front in the middle Atlantic bight. J. Phys. Oceanogr., 31, 2783-2796, https://doi.org/ 10.1175/1520-0485(2001)031<2783:IOASEW>2.0.CO;2.

Griffies, S. M., and R. W. Hallberg, 2000: Biharmonic friction with a Smagorinsky-like viscosity for use in large-scale eddy-permitting ocean models. Mon. Wea. Rev., 128, 2935-2946, https://doi.org/ 10.1175/1520-0493(2000)128<2935:BFWASL > 2.0.CO;2.

Gula, J., M. J. Molemaker, and J. C. McWilliams, 2014: Submesoscale cold filaments in the Gulf Stream. J. Phys. Oceanogr., 44, 26172643, https://doi.org/10.1175/JPO-D-14-0029.1.

Haidvogel, D. B., and Coauthors, 2008: Ocean forecasting in terrainfollowing coordinates: Formulation and skill assessment of the Regional Ocean Modeling System. J. Comput. Phys., 227, 35953624, https://doi.org/10.1016/j.jcp.2007.06.016.
He, R., K. Chen, T. Moore, and M. Li, 2010: Mesoscale variations of sea surface temperature and ocean color patterns at the Mid-Atlantic Bight shelfbreak. Geophys. Res. Lett., 37, L09607, https://doi.org/10.1029/2010GL042658.

Hofmann, E. E., and Coauthors, 2011: Modeling the dynamics of continental shelf carbon. Annu. Rev. Mar. Sci., 3, 93-122, https://doi.org/10.1146/annurev-marine-120709-142740.

Holton, J., 2004: An Introduction to Dynamic Meteorology. 4th ed., Academic Press, 535 pp.

Hoskins, B. J., 1974: The role of potential vorticity in symmetric stability and instability. Quart. J. Roy. Meteor. Soc., 100, 480482, https://doi.org/10.1002/qj.49710042520.

_- 1982: The mathematical theory of frontogenesis. Annu. Rev. Fluid Mech., 14, 131-151, https://doi.org/10.1146/ annurev.fl.14.010182.001023.

—, I. Draghici, and H. C. Davies, 1978: A new look at the $\omega$-equation. Quart. J. Roy. Meteor. Soc., 104, 31-38, https:// doi.org/10.1002/qj.49710443903.

Joyce, T. M., J. K. B. Bishop, and O. B. Brown, 1992: Observations of offshore shelf-water transport induced by a Warm-Core Ring. Deep-Sea Res., 39A, S97-S113, https://doi.org/10.1016/ S0198-0149(11)80007-5.

Kishi, M. J., and Coauthors, 2007: NEMURO-A lower trophic level model for the North Pacific marine ecosystem. Ecol. Modell., 202, 12-25, https://doi.org/10.1016/j.ecolmodel.2006.08.021.

Koszalka, I., A. Bracco, J. C. McWilliams, and A. Provenzale, 2009: Dynamics of wind-forced coherent anticyclones in the open ocean. J. Geophys. Res., 114, C08011, https://doi.org/10.1029/ $2009 \mathrm{jc} 005388$.

Large, W. G., and S. Pond, 1981: Open ocean momentum flux measurements in moderate to strong winds. J. Phys. Oceanogr., 11, 324-336, https://doi.org/10.1175/1520-0485(1981)011<0324: OOMFMI $>2.0 . \mathrm{CO} ; 2$.

— J. C. McWilliams, and S. C. Doney, 1994: Oceanic vertical mixing: A review and a model with a nonlocal boundary layer parameterization. Rev. Geophys., 32, 363-403, https://doi.org/ 10.1029/94RG01872.

Lee, C. M., and K. H. Brink, 2010: Observations of storm-induced mixing and Gulf Stream ring incursion over the southern flank of Georges bank: Winter and summer 1997. J. Geophys. Res., 115, C08008, https://doi.org/10.1029/2009JC005706.

Lehahn, Y., F. d'Ovidio, M. Lévy, Y. Amitai, and E. Heifetz, 2011: Long range transport of a quasi isolated chlorophyll patch by an Agulhas ring. Geophys. Res. Lett., 38, L16610, https:// doi.org/10.1029/2011GL048588.

Lima, I. D., and S. C. Doney, 2004: A three-dimensional, multinutrient, and size-structured ecosystem model for the North Atlantic. Global Biogeochem. Cycles, 18, GB3019, https:// doi.org/10.1029/2003GB002146.

Mahadevan, A., L. N. Thomas, and A. Tandon, 2008: Comment on "Eddy/wind interactions stimulate extraordinary mid-ocean plankton blooms.' Science, 320, 448, https://doi.org/10.1126/ science. 1152111.

Martin, A. P., and K. J. Richards, 2001: Mechanisms for vertical nutrient transport within a North Atlantic mesoscale eddy. Deep-Sea Res. II, 48, 757-773, https://doi.org/10.1016/S0967-0645(00)00096-5.

Mason, E., J. Molemaker, A. F. Shchepetkin, F. Colas, J. C. McWilliams, and P. Sangrà, 2010: Procedures for offline grid nesting in regional ocean models. Ocean Modell., 35, 1-15, https://doi.org/10.1016/j.ocemod.2010.05.007.

McGillicuddy, D. J., 2015: Formation of intrathermocline lenses by eddy-wind interaction. J. Phys. Oceanogr., 45, 606-612, https://doi.org/10.1175/JPO-D-14-0221.1. 
— 2016: Mechanisms of physical-biological-biogeochemical interaction at the oceanic mesoscale. Annu. Rev. Mar. Sci., 8, 125159, https://doi.org/10.1146/annurev-marine-010814-015606.

—, and A. R. Robinson, 1997: Eddy-induced nutrient supply and new production in the Sargasso sea. Deep-Sea Res. I, 44, 1427-1450, https://doi.org/10.1016/S0967-0637(97)00024-1.

—, and Coauthors, 2007: Eddy/Wind interactions stimulate extraordinary mid-ocean plankton blooms. Science, 316, 10211026, https://doi.org/10.1126/science.1136256.

— J. R. Ledwell, and L. A. Anderson, 2008: Response to comment on "Eddy/wind interactions stimulate extraordinary mid-ocean plankton blooms." Science, 320, 448, https:// doi.org/10.1126/science4.1148974.

McWilliams, J. C., L. P. Graves, and M. T. Montgomery, 2003: A formal theory for vortex Rossby waves and vortex Evolution. Geophys. Astrophys. Fluid Dyn., 97, 275-309, https://doi.org/ 10.1080/0309192031000108698.

Molinari, R. L., 1970: Cyclonic ring spin down in the North Atlantic. Ph.D. dissertation, Texas A\&M University, 106 pp.

Nardelli, B. B., 2013: Vortex waves and vertical motion in a mesoscale cyclonic eddy. J. Geophys. Res. Oceans, 118, 5609-5624, https://doi.org/10.1002/jgrc.20345.

Nelson, D. M., and Coauthors, 1985: Distribution and composition of biogenic particulate matter in a Gulf Stream warm-core ring. Deep-Sea Res., 32A, 1347-1369, https://doi.org/10.1016/ 0198-0149(85)90052-4.

— J. J. McCarthy, T. M. Joyce, and H. W. Ducklow, 1989: Enhanced near-surface nutrient availability and new production resulting from the frictional decay of a Gulf Stream warmcore ring. Deep-Sea Res., 36A, 705-714, https://doi.org/10.1016/ 0198-0149(89)90146-5.

Niiler, P. P., 1969: On the Ekman divergence in an oceanic jet. J. Geophys. Res., 74, 7048-7052, https://doi.org/10.1029/ JC074I028P07048.

Okubo, A., 1971: Oceanic diffusion diagrams. Deep-Sea Res. Oceanogr. Abstr., 18, 789-802, https://doi.org/10.1016/00117471(71)90046-5.

Olson, D. B., 1991: Rings in the ocean. Annu. Rev. Earth Planet. Sci., 19, 283-311, https://doi.org/10.1146/annurev.ea.19.050191.001435.

—, R. W. Schmitt, M. Kennelly, and T. M. Joyce, 1985: A twolayer diagnostic model of the long-term physical evolution of warm-core ring 82B. J. Geophys. Res., 90, 8813-8822, https:// doi.org/10.1029/JC090iC05p08813.

O'Neill, L. W., 2012: Wind speed and stability effects on coupling between surface wind stress and SST observed from buoys and satellite. J. Climate, 25, 1544-1569, https://doi.org/10.1175/ JCLI-D-11-00121.1.

Oschlies, A., 2002: Can eddies make ocean deserts bloom? Global Biogeochem. Cycles, 16, 1106, https://doi.org/10.1029/ 2001GB001830.

Pallàs-Sanz, E., and Á. Viúdez, 2005: Diagnosing mesoscale vertical motion from horizontal velocity and density data. J. Phys. Oceanogr., 35, 1744-1762, https://doi.org/10.1175/JPO2784.1.

_ , T. M. S. Johnston, and D. L. Rudnick, 2010: Frontal dynamics in a California current system shallow front: 2. Mesoscale vertical velocity. J. Geophys. Res, 115, C12068, https://doi.org/ 10.1029/2010JC006474.

Pascual, A., S. Ruiz, B. Buongiorno Nardelli, S. Guinehut, D. Iudicone, and J. Tintoré, 2015: Net primary production in the Gulf Stream sustained by quasi-geostrophic vertical exchanges. Geophys. Res. Lett., 42, 441-449, https://doi.org/10.1002/2014GL062569.

Pietri, A., P. Testor, V. Echevin, A. Chaigneau, L. Mortier, G. Eldin, and C. Grados, 2013: Finescale vertical structure of the upwelling system off southern Peru as observed from Glider data. J. Phys. Oceanogr., 43, 631-646, https://doi.org/ 10.1175/JPO-D-12-035.1.

Pollard, R. T., 1970: On the generation by winds of inertial waves in the ocean. Deep-Sea Res. Oceanogr. Abstr., 17, 795-812, https://doi.org/10.1016/0011-7471(70)90042-2.

— , and L. A. Regier, 1992: Vorticity and vertical circulation at an ocean front. J. Phys. Oceanogr., 22, 609-625, https://doi.org/ 10.1175/1520-0485(1992)022<0609:VAVCAA > 2.0.CO;2.

Powell, T. M., C. V. W. Lewis, E. N. Curchitser, D. B. Haidvogel, A. J. Hermann, and E. L. Dobbins, 2006: Results from a threedimensional, nested biological-physical model of the California Current System and comparisons with statistics from satellite imagery. J. Geophys. Res., 111, C07018, https://doi.org/10.1029/ 2004JC002506.

Ryan, J. P., J. A. Yorder, and D. W. Townsend, 2001: Influence of a Gulf Stream warm-core ring on water mass and chlorophyll distributions along the southern flank of Georges Bank. Deep-Sea Res. II, 48, 159-178, https://doi.org/10.1016/ S0967-0645(00)00117-X.

Rypina, I. I., A. Kirincich, S. Lentz, and M. Sundermeyer, 2016: Investigating the eddy diffusivity concept in the coastal ocean. J. Phys. Oceanogr., 46, 2201-2218, https://doi.org/10.1175/ JPO-D-16-0020.1.

Sasaki, K., and Y. Hiroe, 2002: Mechanism of nutrient supply to warm-core ring off Sanriku, Japan. J. Oceanogr., 58, 683-690, https://doi.org/10.1023/A:1022894323424.

Schink, D., J. McCarthy, T. Joyce, G. Flierl, P. Wiebe, and D. Kester, 1982: Multidisciplinary program to study warm core rings. Eos, Trans. Amer. Geophys. Union, 63, 834-835, https:// doi.org/10.1029/EO063i044p00834.

Scemitz, J. E., and A. C. Vastano, 1975: Entrainment and diffusion in a Gulf Stream cyclonic ring. J. Phys. Oceanogr., 5, 93-97, https:// doi.org/10.1175/1520-0485(1975)005<0093:EADIAG > 2.0.CO;2.

Scott, B. D., 1981: Hydrological structure and phytoplankton distribution in the region of a warm-core eddy in the Tasman sea. Aust. J. Mar. Freshwater Res., 32, 479-492, https://doi.org/ 10.1071/MF9810479.

Shchepetkin, A. F., and J. C. McWilliams, 2005: The Regional Oceanic Modeling System (ROMS): A split-explicit, free-surface, topography-following-coordinate oceanic model. Ocean Modell., 9, 347-404, https://doi.org/10.1016/j.ocemod.2004.08.002.

Shcherbina, A. Y., and Coauthors, 2015: The LatMix summer campaign: Submesoscale stirring in the upper ocean. Bull. Amer. Meteor. Soc., 96, 1257-1279, https://doi.org/10.1175/ BAMS-D-14-00015.1.

— E. A. D'Asaro, and S. Nylund, 2018: Observing finescale oceanic velocity structure with an autonomous Nortek acoustic Doppler current profiler. J. Atmos. Oceanic Technol., 35, 411427, https://doi.org/10.1175/JTECH-D-17-0108.1.

Shearman, R. K., J. A. Barth, J. S. Allen, and R. L. Haney, 2000: Diagnosis of the three-dimensional circulation in mesoscale features with large Rossby number. J. Phys. Oceanogr., 30, 2687-2709, https:// doi.org/10.1175/1520-0485(2001)031<2687:DOTTDC>2.0.CO;2.

Siedlecki, S. A., N. S. Banas, K. A. Davis, S. Giddings, B. M. Hickey, P. MacCready, T. Connolly, and S. Geier, 2015: Seasonal and interannual oxygen variability on the Washington and Oregon continental shelves. J. Geophys. Res. Oceans, 120, 608-633, https://doi.org/10.1002/2014JC010254.

Siegel, D. A., P. Peterson, D. J. McGillicuddy, S. Maritorena, and N. B. Nelson, 2011: Bio-optical footprints created by mesoscale eddies in the Sargasso Sea. Geophys. Res. Lett., 38, L13608, https://doi.org/10.1029/2011GL047660. 
Smagorinsky, J., 1963: General circulation experiments with the primitive equations. Mon. Wea. Rev., 91, 99-164, https://doi.org/ 10.1175/1520-0493(1963)091<0099:GCEWTP>2.3.CO;2.

Small, R. J., and Coauthors, 2008: Air-sea interaction over ocean fronts and eddies. Dyn. Atmos. Oceans, 45, 274-319, https:// doi.org/10.1016/j.dynatmoce.2008.01.001.

Smith, R. C., and K. S. Baker, 1985: Spatial and temporal patterns in pigment biomass in Gulf Stream warm-core ring 82B and its environs. J. Geophys. Res., 90, 8859-8870, https://doi.org/ 10.1029/JC090iC05p08859.

Stern, M. E., 1965: Interaction of a uniform wind stress with a geostrophic vortex. Deep-Sea Res. Oceanogr. Abstr., 12, 355367, https://doi.org/10.1016/0011-7471(65)90007-0.

Thomas, L. N., J. R. Taylor, R. Ferrari, and T. M. Joyce, 2013: Symmetric instability in the Gulf Stream. Deep-Sea Res. II, 91, 96-110, https://doi.org/10.1016/j.dsr2.2013.02.025.

Tintoré, J., D. Gomis, S. Alonso, and G. Parrilla, 1991: Mesoscale dynamics and vertical motion in the Alborán Sea. J. Phys. Oceanogr., 21, 811-823, https://doi.org/10.1175/1520-0485(1991) 021<0811:MDAVMI>2.0.CO;2.

Tranter, D. J., R. R. Parker, and G. R. Cresswell, 1980: Are warmcore eddies unproductive? Nature, 284, 540-542, https:// doi.org/10.1038/284540a0.

Viúdez, Á., 2018: Two modes of vertical velocity in subsurface mesoscale eddies. J. Geophys. Res. Oceans, 123, 3705-3722, https://doi.org/10.1029/2017JC013735.
, and D. G. Dritschel, 2004: Potential vorticity and the quasigeostrophic and semigeostrophic mesoscale vertical velocity. J. Phys. Oceanogr., 34, 865-887, https://doi.org/10.1175/15200485(2004)034<0865:PVATQA > 2.0.CO;2.

__ J. Tintoré, and R. L. Haney, 1996: About the nature of the generalized omega equation. J. Atmos. Sci., 53, 787-795, https://doi.org/10.1175/1520-0469(1996)053<0787:ATNOTG> 2.0.CO;2.

Wenegrat, J. O., and L. N. Thomas, 2017: Ekman transport in balanced currents with curvature. J. Phys. Oceanogr., 47, 1189-1203, https://doi.org/10.1175/JPO-D-16-0239.1.

Xie, S.-P., 2004: Satellite observations of cool ocean-atmosphere interaction. Bull. Amer. Meteor. Soc., 85, 195-208, https:// doi.org/10.1175/BAMS-85-2-195.

Zhang, W. G., and G. G. Gawarkiewicz, 2015: Dynamics of the direct intrusion of Gulf Stream ring water onto the MidAtlantic Bight shelf. Geophys. Res. Lett., 42, 7687-7695, https://doi.org/10.1002/2015GL065530.

— D. J. McGillicuddy, and G. G. Gawarkiewicz, 2013: Is biological productivity enhanced at the New England shelfbreak front? J. Geophys. Res. Oceans, 118, 517-535, https://doi.org/ 10.1002/jgrc.20068.

Zhang, Z., B. Qiu, P. Klein, and S. Travis, 2019: The influence of geostrophic strain on oceanic ageostrophic motion and surface chlorophyll. Nat. Commun., 10, 2838, https://doi.org/10.1038/ s41467-019-10883-w. 